\title{
IX.
}

\section{Das Larynxödem und die submucöse Laryngitis.}

(Aus dem städtischen Krankenhause am Urban zu Berlin.)

Von Dr. A. Kuttner, Berlin.

(Hierzu Taf. IV.)

In der zweiten Auflage der Eulenburg'schen Real-Encyclopädie findet sich ein von Tobold unterzeichneter Artikel, welcher folgende Ueberschrift trägt: Larynxödem, Oedema glottidis, Laryngitis submucosa, Laryngitis oedematosa, Laryngitis phlegmonosa, Angina laryngea infiltrata, Laryngitis sero-purulenta, Laryngitis submucosa purulenta, Angina laryngea oedematosa.

All' diese Namen, die zu den verschiedensten Zeiten und von den verschiedensten Autoren vorgeschlagen worden sind, sollten zur Bezeichnung einer ganz bestimmten Gruppe von Kehlkopferkrankungen dienen; man glaubte nehmlich alle Fälle, bei denen eine ödematöse oder eitrige Durchtränkung irgend welcher Larynxtheile zu constatiren war, als zusammengehörig auffassen zu müssen. Als Bindeglied für die einzelnen, im Uebrigen durchaus verschieden gearteten Fälle galt eben diese seröse oder eitrige Durchtränkung.

Es liegt auf der Hand, dass sich auf Grund eines so vagen Eintheilungsprincipes ein präcises Krankheitsbild nicht construiren lassen konnte. Da aber alle Fälle durchaus von diesem einen Gesichtspunkt aus beurtheilt werden sollten, so musste, was bei der Verschiedenartigkeit der Einzelerkrankungen gewiss nicht wunderbar erscheinen kann, die ursprüngliche Krankheitsdefinition sich mancherlei Aenderung und Umgestaltung gefallen lassen, bis schliesslich anstatt der einen eine ganze Reihe von Definitionen vorhanden waren, von denen jede ihre Signatur in Form eines neuen Namens mit auf den Weg erhielt: die Reihe der Benennungen, die so im Laufe der Zeiten vorgeschlagen sind, geht noch weit über die oben citirte Reihe hinaus.

Bis in die neueste Zeit hinein hat dieser Ueberfluss von Namen nicht gerade klärend auf die Sache selbst gewirkt. Die 
8
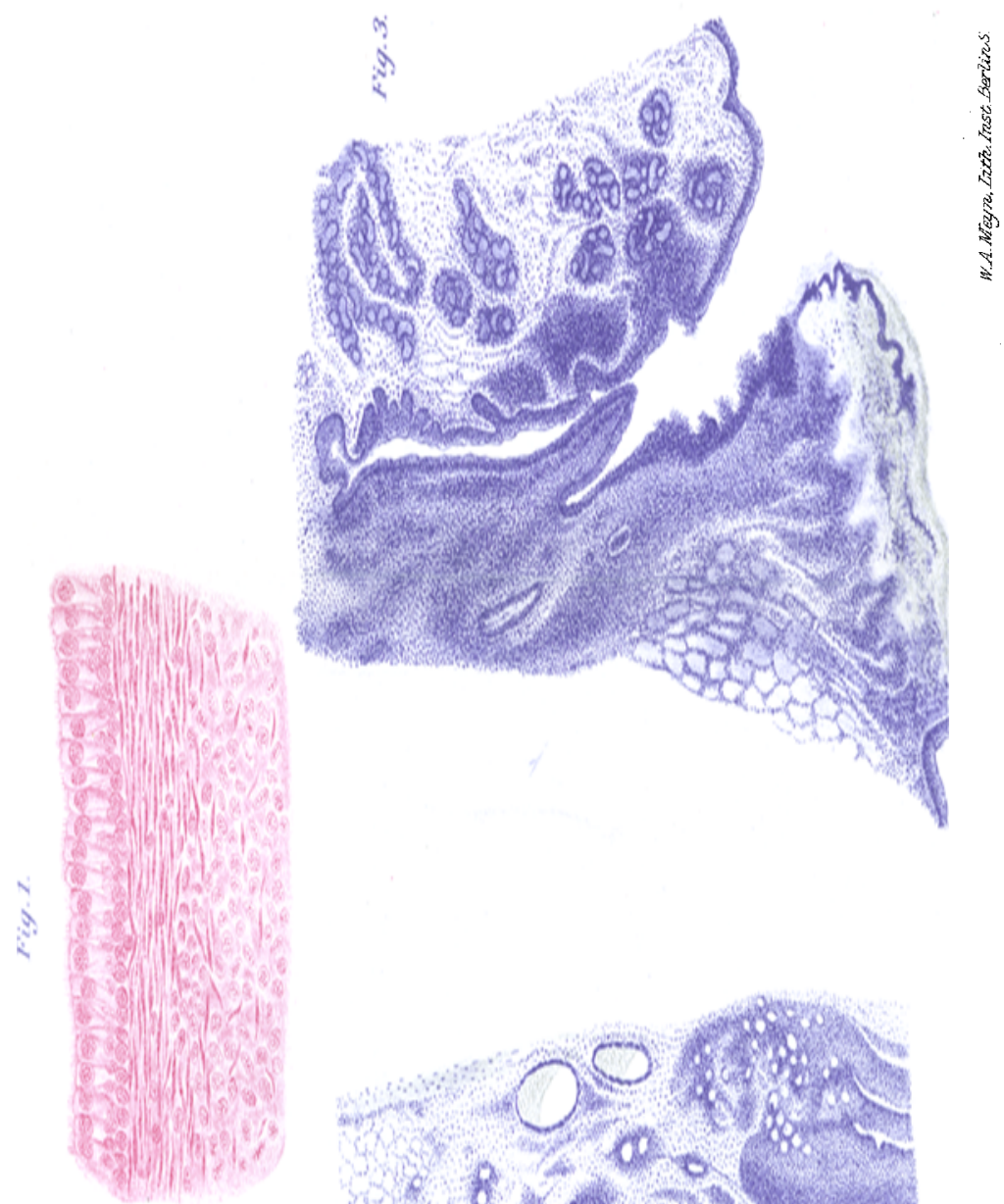

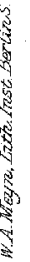

है

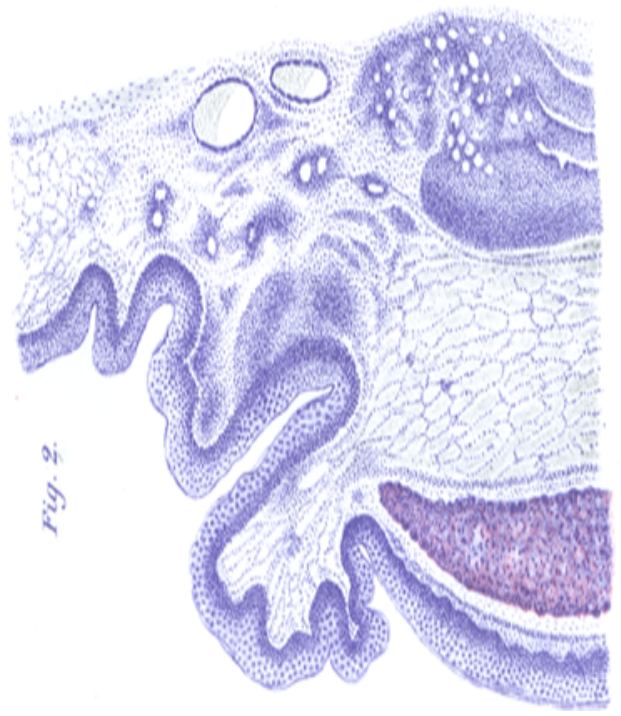


Mehrzahl der Autoren hat es vorgezogen, die Gesammtmaterie in mehrere Krankheitsbilder zu gliedern, zu deren näherer Bestimmung bald diese, bald jene von den oben angeführten Bezeichnungen als Capitelüberschrift herangezogen wurde: es sollte also schon in der Verschiedenheit der Namen die Verschiedenartigkeit der jeweiligen Krankheitsprozesse zum Ausdruck gebracht werden.

Andere haben sich von der alten Schablone noch nicht frei machen können und drängen das ganze Material in ein einziges Kraukheitsbild zusammen. Diese gebrauchen all' die oben citirten Namen unterschiedslos zur Bezeichnung für ein und dieselbe, ihrer Meinung nach durchaus einheitliche Sache. Dieselben Benennungen also, die in dem einen Lehrbuch streng von einander geschieden und zur Charakterisirung sachlicher Gegensätze verwendet werden, werden in dem anderen ganz promiscue gebraucht und jedes wesentliche, in der Sache selbst begründete Unterscheidungsmoment wird für dieselben geleugnet.

In dem letzten Jahrzehnt haben nun allerdings Massei und Senator aus diesem Chaos eine Reihe von Fällen herausgehoben, die sich auf Grund ihrer eigenthümlichen klinischen oder ätiologischen Verhältnisse in den Rahmen besonderer Krankheitsbilder einfügen liessen. Manche Affection, die bis dahin vollkommen verkannt wurde, ist hierdurch dem allgemeinen Verständniss näher gerückt worden. Aber die Vorarbeiten, auf welche sich diese beiden Autoren bei ihren Untersuchungen stützten und die damals über jeden Zweifel erhaben schienen, haben sich in neuerer Zeit in manchem Punkte als so unzuverlässig erwiesen, dass die Schwäche des Fundamentes den ganzen Bau zu gefährden droht.

Was Wunder also, wenn in jedem Lehrbuch und in jeder diesbezüglichen Arbeit die Klage laut wird, dass die Capitel, die das Laryoxödem, die submucöse und die phlegmonöse Entzündung, das Erysipel und die acut infectiöse Phlegmone behandeln, immer noch einer endgültigen Ordnung harren?

Einen solchen Versuch zu wagen, ist der Zweck vorliegender Arbeit ${ }^{1}$ ).

1) Eine ausfübrliche Monographie unter gleichem Titel über dasselbe Thema erscheint binnen Kurzem rom Verf. in der Verlagsbuçhandlung ron Georg Reimer (Berlin). 
Von dem Krankenmaterial, dessen Beobachtung meinen Cntersuchungen zu Grunde liegt, entstammen drei Fälle meiner eigenen Praxis und sechs Fälle dem städtischen Krankenhaus am Urban. Den Directoren dieser Anstalt, Herrn Prof. Dr. A. Fraenkel und Herrn Dr. W. Körte, welche mir mit freundlichstem Entgegenkommen die Untersuchung dieser Patienten und die Veröffentlichung ihrer Krankenberichte gestatteten, fühle ich mich zu lebhaftem Dank verpflichtet.

I. F. Z., 27jäbriger Arbeiter, am 14. Juli eingeliefert in die innere Abtheilung des Städtischen Krankenhauses am Urban.

Patient giebt an, dass er seit 14 Tagen cr. an Husten und Schnupfen leidet, sich aber trotzdem bis zum 13. Juli vollkommen wohl befunden habe. An diesem Tage empfand er zum ersten Male in den späten Abendstunden beim Schlucken ein scbmerzhaftes Gefühl auf der rechten Seite des Keblkupfes; während der Nacht wurden diese Beschwerden bedeutend stärker und es stellten sich Erstickungsanfälle ein. Am 14. Juli wurde folgender Status aufgenommen:

Die Athmung des kräftig gebauten Patienten ist regelmässig, aber ausgesprochen dyspnoisehen Charakters; In- und Exspiration sind von Stridor begleitet.

Der Pharynx zeigt eine leichte Röthung.

Der ganze Aditus laryngis - Epiglottis, Ligg. ary-epiglottica und die Schleimbaut über den Aryknorpeln - ist sebr stark geschwollen und gerötbet. Die rechte Seite stärker als die linke. Der rechte freie Rand der Epiglottis ist von einem dicken, grauweissen fibrinösen Belage bedeckt, der sich über das Lig. ary-epiglottic. bis zum Aryknorpel hinzieht. Von der Vorderfläche dieses bängt ein tumorartiger, ödematöser Sack in das Innere des Kehlkopfes hinein, der bei jeder Inspiration tief in den Larynx angesaugt wird. Die tiefergelegenen Partien sind für die Besicbtigung unzugänglich. Die Sinus pyriformes beiderseits versehwollen.

Submaxillardrüsen stark gescbwollen; Organe des Thorax und des Abdomens normal, Urin klar, ohne Albumen.

Wegen der häufig sich wiederholenden Erstickungsanfälle incidirte ich noch an demselben Abend die ödematöse Blase. Hierbei entleerte sich aus derselben etwa ein halber Theelöffel einer wasserhellen, klaren Flässigkeit; diese Blase fiel dann zusammen und hat sich wäbrend der ganzen Krankheitsdauer nicht wieder gefüllt. Die Atbmung blieb zwar auch nach diesem Eingriff noch längere Zeit dyspnoisch, aber die Erstickungsanfälle waren dauernd beseitigt.

Am 15. Juli war die Schwellung auf der linken Larynxbälfte eben so stark als auf der rechten.

Vom 16. Juli an begann die Intensität des Krankbeitsprozesses nachzulassen; zuerst wurde die Athmung freier; die Schluckbeschwerden wichen 
erst viel später. Die Anschwellung ging erst auf der linken, viel später auf der rechten Seite zurück. Im Larynxinnern siebt man jetzt, wo ein besserer Einblick möglich ist, an verschiedenen Stellen (Taschenbändern, hinterer Wand, rechtem Stimmband) tiefgreifende Erosionen, die mit schmutzig-granen Fetzen bedeckt sind. Das rechte Crico-Arytänoidgelenk steht fest. Erst am 27. Juli hat sich die Schleimbaut vollkommen gereinigt und vom 28. Juli an ist wieder eine Beweglichkeit des rechten Aryknorpels zu constatiren. Am 28. August wird Pat. aus der Behandlung entlassen; eine leichte Röthung des rechten Stimmbandes und ein leises Druckgefühl beim Schlucken erinnern noch an die überstandene Krankheit - auch diese verloren sich innerhalb der nächsten 4 Wochen - jede Schwellung und jede Bewegungsstörung im rechten Crico-Arytänoidgelenk ist verschwunden.

$$
\begin{aligned}
& \text { 14. Juli Temp. 38,2, 38,6 Puls } 114 \text { Resp. } 36 . \\
& \text { 15. - - } 37,0,38,0 \quad-104-24 \text {. } \\
& \text { 16. - - } \quad 37,2,38,1-102-24 \text {. } \\
& \text { 17. - }-37,1,38,0-106-24 . \\
& \text { 18. - - } 37,2,37,8 \quad-96 \quad-20 .
\end{aligned}
$$

Vom 19. Juli an waren Temperatur, Puls und Respiration normal.

II. G. I., 42 Jahre, Bankdirector, batte am 1. Juli mit seiner Familie eine neue Wohnung bezogen, welche 6 Monate lang vorher unvermiethet gewesen war. Es erkrankten unmittelbar nach dem Cmzuge der Reihe nach 5 Kinder, 2 Dienstmädchen, die Fran und zuletzt der Herr des Hauses nur ein Kinderfräulein blieb verschont - an Angina lacunaris. Bei einem Kinde stellte sich im Anschluss an diese Angina eine acute eitrige Mittelohrentzündung mit spontaner Perforation des Trommelfelles ein, bei der Mutter geselite sich zu der ersten Erkrankung ein starker Schnupfen, nebst Scbwellung und Rötbung der Nasenspitze, die aber obne besondere Bebandlung beilten. Herr G. selbst erkrankte als letzter in der Familie, und seine Angina nahm einen typischen Verlauf. Am $2 \dot{2}$. April fühlte er sich wieder ganz gesund und frei von jeder Beschwerde, so dass er seinen Geschäften nachging; Tags darauf aber empfand er von Neuen Unbequemlicbkeit beim Schlucken, nur sass diesmal der Schmerz etwas tiefer; in der Nacht traten öftere Erstickungsanfälle ein; am 24, wurde ich ron dem Hausarzt der Familie citirt und fand folgenden Status:

Pharynxschleimbaut geröthet und leicht angeschwollen.

Alle Theile des Aditus laryngis sind tiefroth und bis fast auf das Dreifache ibrer normalen Verhältnisse verdickt; das Gewebe ist überall tief und derb infiltrirt nirgends eine Spur von Oedem zu sehen. Vom rechten Rande der Epiglottis zum rechten Aryknorpel zieht sich ein grauweisser, fest aufsitzender Belag.

Die Stimme des Patienten ist heiser; der Kehlkopf sehr empfindlich gegen Berührung, die Athmung in der Ruhe verhältnissmässig frei; bei jeder Bewegung aber, welche der Patient macht, tritt hochgradige Athemnoth ein. Nachdem sich das Krankheitsbild 2-3 Tage ziemlich unverändert er- 
halten hatte, trat allmähliche Reinigung und Abschwellung der Schleimhaut ein - auch hier schwand erst die Athemnoth und nachher die Schluckbeschwerden. Am 29. April besucbte ich den Patienten zum letzten Mal, am 2. Mai stellte sich derselbe vollkommen geheilt in meiner Wobnung vor.

$$
\begin{aligned}
& \text { 24. April Temp. 38,7 Puls } 110 . \\
& 25 \text { - } \quad-\quad 38,3,38,7 \quad-108 \text {. } \\
& 26 \text { - } \quad-\quad 37,8,38,1-108 . \\
& 27 \text { - } \quad-37,3,37,8 \quad-100 .
\end{aligned}
$$

Von da an blieben Puls und Temperatur normal.

III. Rf. E., 16jähriges, kräftig gebautes Mädchen, erkrankte am 9. März plötzlich mit Halsbesebwerden und Heiserkeit. Am 12. traten Anfälle von Athemnoth auf, derentwegen Patientin am 13, auf die äussere Station des Krankenhauses am Urban gebracht wurde, woselbst folgender Status aufgenommen wird:

Ueber den Lungen nichts Abnormes.

Pbarynxschleimhant weder geröthet noch geschwollen, keine Beläge.

Epiglottis leicht geschwollen, beweglich. Die Schleimhaut über beiden Aryknorpeln zeigt starke Schwellung mit ödematöser Durchtränkung, welche auf beide Ligg. ary-epiglottica und beide Taschenbänder übergreift (links ist die Schwellung stärker als rechts), so dass nur ein schmaler Streifen von beiden Stimmbändern sichtbar wird. Diese, nur einen ganz schmalen Spalt zwischen sich lassend, sind augenscheinlich weit weniger beweglich als in gesundem Zustand. Die Adduction ist mangelhaft, die active Abduction scheint aufgehoben zu sein.

Am 14. wird in Folge der immer bedrohlicher werdenden Athemnoth die Tracheotomie ausgeführt.

Vom 17. an tritt eine Besserung des Larynxbefundes ein; zuerst geht die rechtsseitige, dann die linksseitige Schwellung zurück; das rechte Stimmband bewegt sich normal, das linke steht dicht neben der Mittellinie unverrückbar fest und ist immer noch roth und geschwollen. Erst 14 Tage etwa nach der Operation fing das linke Stimmband an leichte Abductionsbewegungen zu machen, Schwellung und Röthung fingen an sich zurückzubilden, und erst nach weiteren 14 Tagen war der Larynxbefund wieder normal.

$\begin{array}{llllll}\text { 14. März } & \text { Temp. } & 38,8 . & \\ \text { 15. } & - & - & 38,2, & 38,6, & 39,2 . \\ \text { 16. } & - & - & 37,5, & 38,9, & 38,9 . \\ \text { 17. } & - & - & 37,3, & & 38,4 . \\ \text { 18. } & - & - & 37,2, & & 37,8 . \\ 19 . & - & - & 37,0, & & 38,0 .\end{array}$

Von da an normal.

IV. Sch. M., 38 Jahre, Tischler.

Pat. erkrankte am 20. März des Abends nach einem, Tags zuror stattgehabten, starken Excesse in Baccho. Es traten plötzlich Heiserkeit, 
Schluckbeschwerden anf, die sich am 21. so ausserordentlich steigerten, dass der Kranke am 22. die Aufnabme auf der inneren Abtheilung des Urbankrankenhauses nacbsuchte.

Bauch- und Brustorgane sind normal.

Urin missfarben, trübe, mit Spuren von Albumen und reichlichem Indican, obne mikroskopischen Befund.

Die Gebilde des Pharynx sind normal.

Epiglottis, Ligg. ary-epiglottic. und die Sebleimbaut über den.Aryknorpeln sind enorm verdickt, von blutrother Farbe, aber etwas durchscheinend, in Folge von seröser Durchtränkung des Gewebes. Die Stimmbänder sind ziemlich gut sicbtbar, sie sind nur wenig geröthet und von normaler Beweglichkeit. Auf der Epiglottis liegen punktförmige, auf den Taschenbändern mehr flächenhafte Auflagerungen, von grauweisser Farbe. - Die Submaxillardrüsen ein wenig gescbwollen.

Bis zum 28. war der objective Befund unverändert; an diesem Tage ist Pat., der übrigens durchaus nicht den Eindruck eines Schwerkranken macht, etwas beiserer als vordem; das rechte Stimmband ist ziemlich lebhaft geröthet und steht nahe der Mittellinie still. Die oben geschilderten, der Schleimbaut aufliegenden Membranen haben sich an einzelnen Stellen abgestossen, an anderen sind neue sichtbar geworden. Erst vom 30. an macht sich eine erhebliche Abnahme der Schwellung geltend; die Stimme bessert sich, bleibt aber immer woch rauh. Am 4. April fängt das rechte Stimmband wieder an, Abductionsbewegungen zu machen. Am 8. wird Pat., der sich schon seit einiger Zeit beschwerdefrei füblt, aus der Bebandlung entlassen. Bis auf das rechte Stimmband, dessen Farbe und Beweglichkeit noch nicht vollkommen normal sind, sind alle Spuren der Erkrankung gewichen.

\begin{tabular}{|c|c|c|c|c|c|}
\hline 2. März & Temp. & $38,5,38 ; 2,38,6,38,1,39,4$ & Puls & 120 & Resp. \\
\hline 3. & - & $38,5,38,5,39,2,39,0,38,3$ & - & 116 & _ \\
\hline- & - & $37,4,37,6,36,6,38,8,38,4,38,1$ & - & 72 & - \\
\hline- & - & $37,5,37,4,37,7,39,4,38,7,37,3$ & - & 84 & - \\
\hline - & - & $36,7,38,6,36,9,37,5,37,5$ & - & 72 & - \\
\hline
\end{tabular}

Vom 27. März an normal.

V. W. I., 43 Jabre, Werkmeister, leidet seit 4 Tagen beim Schlucken an Schmerzen in der Kehlkopfgegend, die nach beiden Ohren ausstrahlen. Bei Beginn seiner Erkrankung fühlte sich Pat., der sehr angegriffen aussieht und fast gar nichts zu sich nehmen kann, fieberbaft; doch waren die Fiebererscheinungen in den letzten Tagen geringer.

15. Juli. Organe der Brust und Bauchhöhle normal.

Rachengebilde zeigen keine Veränderung.

Die Epiglottis ist stark verdickt, in einen starren, glasig-durchscheinenden Wulst verwandelt. Die Schwellung greift auf beide Ligg. ary-epiglottica über. Der Einblick in den Aditus laryngis ist durch die Unbeweglichkeit der Epiglottis ausgeschlossen. 
Ich stach an der lingualen Fläche der Epiglottis mit einer für den Kehikopf eingerichteten Pravaz'schen Spritze ein und aspirirte etwas blutigserôse Flüssigkeit. Ein aus dem Inneren der Spritze anf Agarplatten ausgestricbener Tropfen ergab Reinculturen von Staphylococcus pyogenes aureus.

Am 18. war die Schwellung am Aditus laryngis so weit zurückgegangen, dass man das Keblkopfinnere übersehen konnte. Die Schleimhaut war überall leicht gerōthet, docb waren keine tiefergreifenden Veränderungen vorhanden.

Die Temperatur, die des Abends gewöhnlich bis etwa auf 38,20 gestiegen war, blieb vom 17. an normal.

Die Schluckbeschwerden und Entzündungserscheinungen am Kehlkopf gingen ziemlich langsam vorüber; erst 16 Tage nach seiner ersten Vorstellung konnte Pat. als geheilt aus der Behandlung entlassen werden.

Von Interesse ist noch, dass Pat. gerade vor Jabresfrist genau dieselben Beschwerden gehabt hat; damals wurde von berufenster Seite seine Epiglottis scarificirt, worauf ganz allmählich die Beschwerden nachliessen. 4 Wochen nach jener ersten Attacke stellte sich ein Recidiv ein; wieder wurde eine Scarification vorgenommen, wonach allmäblich Heilung eintrat.

VI. D. W., 40 Jabre, Sattler, erkrankte vor 3 Tagen plötzlich unter leichten Fiebererscheinungen mit drückenden Schmerzen in der Keblkopfgegend, die jedesmal beim Schlucken und Sprechen heftiger wurden.

Der am 15. September in meiner Poliklinils anfgenommene Befund lautet: Vom linken Aryknorpel ausgehend eine hochgradige Schwellung und Röthung der ganzen linken Hälfte des Aditus laryngis. Die linke Hälfte der Epiglottis und das linke Lig. ary-epiglottic. sind so stark geschwollen, dass das Stimmband vollkommen verdeckt wird. Der Einblick in den linken Sin. pyriform. ist durch die Scbwellung der angrenzenden Larynxtheile verdeckt. Nach rechts bin fällt die Schwellung der Epiglottis ailmählich ab.

Auch die linke Plica salpingo-pharyngea ist stark geschwollen und eben so wie das Lig. ary-epiglott. mit grauweissen, punktförmigen, fibrinösen Belägen besetzt. Die Tonsillen und die übrigen Pharynxtheile sind normal.

Pat. ist fieberfrei. Die Abendtemperaturen konnten nicht erhoben werden.

Binnen 4 Tagen unter Verabreichung von Eis vollkommene Heilung.

VII. W. W., 33 Jahre, Metallarbeiter, fühite am 9. März 1893 zum ersten Male beim Schlucken leichte Schmerzen in der Kehlkopfgegend, die ganz allmäblich stärker wurden und nach dem linken Ohre hin ausstrahlten.

Am 13. zeigte sich die Nasenspitze ein klein wenig geschwollen und geröthet.

Pat. hat seine Thätigkeit bis zum 15, wo er sich in meiner Poliklinik vorstellte, nicht ausgesetzt; von Fiebererscheinungen bat er nach seiner Angabe nicht viel gelitten.

Der am 15. aufgenommene Befund lautete:

Die Epiglottis (besonders die linke Hälfte), das linke Lig. ary-epiglottic. und die Schleimbant über dem linken Aryknorpel sind stark geschwollen 
und ödematös durchtränkt; der ganze weiche Gaumen ist hochgradig geröthet und geschwollen, die Uvula ödematös:

Die äussere Nasenspitze, geröthet, teigig geschwollen, zeigt Blasen mit serösem Inhait gefüllt.

Pat. ist fieberfrei (nur Vormittags gemessen).

Am 16. beginnen die Blasen auf der Nasenspitze einzutrocknen; die Oedeme im Pharynx und Larynx sind im Schwinden begriffen.

Am 18. sind bis auf eine ganz kleine Röthung der Schleimbäute alle Erscheinungen geschwunden. Pat. hat keine subjectiven Beschwerden mehr. Die Heilung kann von dem nächsten Tage an als eine rollkommene betrachtet werden.

VIII. G. W., 42 Jahre alt, Arbeiter; innere Station des Städtischen Krankenbauses am Urban.

Pat. leidet seit längerer Zeit an Husten, seit 14 Tagen an Heiserkeit und Schluckbeschwerden, besonders schmerzhaft ist die rechte Seite; seit 2 Tagen ist der Kranke aphonisch und bat mit starker Athemnoth zu kämpfen.

Pat. wird am.2. December in's Krankenhaus eingeliefert in starker Prostration; er nimmt im Bett eine halbsitzende Lage ein, die Athmung ist angestrengt und röchelnd.

Ueber beiden Lungen diffuse katarrhalische Geräusche.

Pharynxschleimhaut leicht geschwollen, keine Beläge.

Epiglottis, Ligg. ary-epiglottica und die hintere Umgrenzung des Kehlkopfeinganges zeigen eine graurothe Farbe und bocbgradige derbe Schwellung, kein Oedem. An den freien Rändern der Epiglottis schmutziggraue, fibrinöseitrige Beläge. Ulcerationen sind nirgends wahrnebmbar. Das Keblkopfinnere ist mit schleimig-eitrigen, sich immer wieder ergänzenden Massen ausgefüllt, so dass ein Einblick in dasselbe nicht gewonnen werden kann.

Submaxillar- und Inguinaldrüsen beiderseits gesebwollen.

Der Auswurf ist übelriechend, vierschichtig und leicht röthlich gefärbt.

Der Urin rothgelb, leicht getrübt.

Da die Atbemnoth bis zum 4. December immer bedrohlicher, der Puls immer schlechter wird, schreitet man zur Tracheotomie. Während derselben tritt der Exitus ein.

\begin{tabular}{|c|c|c|c|c|c|c|}
\hline December & Temp. & & $38,2,38,2$ & Puls & 126 & Resp. \\
\hline - & - & $37,7,38,4$, & $38,0,38,2$ & 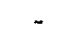 & 128 & - \\
\hline - & - & $38,1,38,0$ & & - & 126 & - \\
\hline
\end{tabular}

Die Section des Kehlkopfes ergab folgendes Resultat: Zwischen dem Os byoides und dem oberen Rande der Cartilago thyreoidea findet sich rechterseits, bedeckt von den oberfächlichen Muskeln, ein Erweichungsheerd von der Grösse einer Haselnuss inmitten eines missfarbigen Gewebes. Von hier aus lässt sich die Eiterung nach unten verfolgen bis zur Cart. thyreoid., wo dieselbe, unter theilweiser Ablösung des Perichondriums, sich auf der vorderen und binteren Wand des Knorpels einen Weg gebabnt hat. - In der Tiefe des Sinus pyriformis dexter findet sich ein zweiter, gleichfalls 
nicht scharf abgesetzter Erweichungsheerd, in dessen Umgebung die Muskeln missfarbig und mit Eiter durchtränkt sind.

Die gesammte Schleimhaut des Kehlkopfes - so wohl der Aditus laryngis als die Stimmbänder und die subglottischen Theile - ist enorm geschwollen, fühlt sich derb an und zeigt auf dem Durchschnitt eine gleichmässige, graugelbe, speckige Infiltration.

Die bakteriologische Untersuchung des Eiters bei der Section ergab Reincultur von Streptococcus pyogenes. Ausserdem ergab die Section Pneumonien in beiden Unterlappen und eine frische serös-eitrige Pericarditis.

IX. S. E., 21 Jabre alt, Dienstmädchen, erkrankte am 13. November mit Schüttelfrost, Schmerzen im Kreuz, Kopf und Hals. Da Pat. sich immer kränker fühlte und besonders die Schluckbeschwerden an Heftigkeit zunahmen, suchte dieselbe am 16. November das Krankenhaus auf.

16. November. Rachenorgane leicht geröthet, Tonsillen etwas geschwollen, kein Belag. Die den Kehlkopfeingang umschliessenden Theile in toto stark geschwollen, so dass ein Einblick in das Innere desselben nicht gewonnen werden kann. Die Schleimhaut ist missfarbig und stellenweise mit grawweissen membranösen Belägen bedeckt.

Rechtsseitiges pleuritisches Exsudat.

Am 17. November stellten sich zum ersten Male von Seiten des Kehlkopfes Stenosenerscheinungen ein, die am 20. November zur Tracheotomie führten. Am 22. November trat, ohne dass sich eine nennenswerthe Veränderung in dem Befunde der Halsorgane bemerkbar gemacht hätte, der Exitus lethalis ein. Temperatur 39-40,1. Puls 120-144. Respiration 24-36.

Sectionsprotocoll: Beide Tonsillen geschwollen, von grauröthlicher Farbe, auf dem Durchschnitt von markiger Beschaffenheit. Das retropharyngeale Zellgewebe ist normal. Epiglottis, Ligg. ary-epiglottica und hintere Larynxwand sind stark geschwollen und hyperämisch, die Schleimhaut bis zu den Taschenbändern von missfarbiger Beschaffenheit und vielfach mit schwutzigen, graugelben Belägen bedeckt, die mit der darunterliegenden Schleimhaut continuirlich zusammenhängen; bei dem Versuch, dieselben mittelst der Pincette zu entfernen, folgt die Schleimhaut in mehr oder weniger grosser Ausdebnung. Schwellung und Beläge reichen bis zu den Stimmbändern herunter.

Auf dem Durchschnitt zeigt sich das Larynxgewebe überall gleichmässig infiltrirt, nirgends findet sich ein Eiterheerd.

Die bakteriologische Untersuchung des Gewebssaftes aus Herz, Milz, Lunge, Larynx und peritracbealem Bindegewebe ergiebt Reinculturen von Streptococcus pyogenes.

Epikrise. Massei hatte sich in seiner Monographie „über das primäre Erysipel des Kehlkopfes" die Aufgabe gestellt, den Nachweis zu führen, dass eine ganze Reihe von Fällen, die früher als primäre Kehlkopfödeme bezeichnet wurden, den Charakter 
einer acuten allgemeinen Infectionskrankheit tragen, und dass die Localaffection des Larynx bei solchen Erkrankungen nur als eine locale Reaction desjenigen Organs aufzufassen sei, das zufälligerweise die Eingangspforte für das inficirende Virus darstellt. Der Autor hatte 14 Krankengeschichten mitgetheilt, die in ibren wichtigsten Punkten eine fast vollkommene Uebereinstimmung zeigen. In allen Fällen handelt es sich um ganz acut und fieberhaft einsetzende, primäre Erkrankungen des Kehlkopfes. Die Fiebercurve zeigt gewöhnlich ziemlich beträchtliche Schwankungen, bei denen man Maxima und Minima, Remissionen und eventuelle Nachschübe, wie sie bei vielen Infectionskrankheiten üblich sind, erkennen kann. Als locale Erkrankung des Kehlkopfes wird gewöhnlich eine hochgradige Schwellung, beziehungsweise Infiltration derjenigen Theile, die den Aditus laryngis einfassen, angegeben. Als subjective Symptome machen sich geltend grosse Abgeschlagenheit und Mattigkeit, Erschwerung der Athmung und Schmerzhaftigkeit beim Schlucken.

Dieses Symptomenbild glaubte Massei als primäres Larynxerysipel deuten zu müssen, wobei ihm „der laryngoskopische Befund zusammengehalten mit der Acuität des Verlaufes und mit der Fiebercurve" (S. 44) für die Diagnose maassgebend ist.

Die Annahme eines Larynxerysipels, und selbst die eines primären, war an sich nichts Neues. Schon Hippokrates spricht in seinem Buch der Vorhersagungen ${ }^{1}$ ) vom Erysipel des Rachens und der tieferen Luftwege. Die erste Darstellung aber, die das primäre Larynxerysipel in treffender Weise vom secundären unterscheidet, findet sich bei Ryland ${ }^{2}$ ); derselbe beschreibt „in the first place, cases (of the erysipelatous laryngitis) where the morbid action was propagated from the face to the fauces and larynx; and, in the second place, other cases, in which the inflammation of the internal organs was unaccompanied by external erysipelas (p. 59). Um aber die Diagnose eines primären Larynxerysipel stellen zu können, hielt er es für nothwendig, dass die betreffenden Fälle "occured in an hospital, where erysipelas was, at the time of their occurence,

1) Praenotionum liber. No, 171-173.

2) Ryland, A treatise on the diseases and injuries of the Larynx and Trachea. London 1837. 
exceedingly prevalent, and that in their anatomical characters bear so close a resemblance to the cases that have just been cited (extension of erysipelas from the face to the larynx), that I have not hesitated to call them erysipelatous laryngitis" (p. 72).

Diese von Ryland formulirten Principien blieben maassgebend für all' die folgenden Autoren, die sich mit unserem Thema beschäftigten; es sind hier besonders zu nennen Budd, Porter, Cornil, Friedreich, Pitha und Mackenzie; den beiden letzteren war gelegentlich des epidemieartigen Auftretens von septischen Erkrankungen ein gewisser Genius epidemicus des Larynxödems aufgefallen. - Massei aber war der erste, und darauf beruht das grosse Verdienst seiner Arbeit, der eine primäre und directe Infection des Kehlkopfes auch in den Fällen annahm, wo die Patienten zu keinem anderen an Erysipel leidenden Kranken in irgend welche nachweisbare Beziehung getreten waren. Diese Entdeckung war von hervorragender Bedeutung, aber Massei schiesst auf der anderen Seite wohl ein wenig über das Ziel hinaus, wenn er (S. 44) "von der Diagnose des primären Larynxerysipels auch diejenige Form der Larynxrose ausschliesst, welche bei Kranken sich entwickeln kann, die in einem von epidemischen Erysipel befallenen Saale eines Hospitals liegen“. Denn wenn ein Patient beispielsweise mit einer Luxatio femoris in einem solchen Krankenhause an der eben geschilderten Larynxaffection erkrankt, ohne dass irgend eine andere Stelle seines Körpers eine Spur von Erysipel aufweist, so wüsste ich wahrlich. nicht, wie Massei diese Affection anders denn als primäres Larynxerysipel bezeichnen wollte.

Die neue Lehre Massei's fand fast durchgehends bedingungslose Anerkennung und weitere Mittheilungen von v. Bergmann, Dalavan, Davis, Henning, Nerrigan, Marais, Fasano, Biondi, Hajek, Samter, Jürgensmeyer, Pettesohn, Ziegler und Herzfeld brachten derselben Bestätigung.

Soll diese Lehre nun zu Recht bestehen, so wäre zu beweisen: 1) dass die fragliche Erkrankung in der That eine acute, allgemeine Infectionskrankheit darstellt und 2) dass die Localaffection, welche bei dieser allgemeinen Erkrankung im Kehlkopf 
ausgelöst wird, wirklich erysipelatöser Natur ist. Während die erste Frage immer und überall rückhaltslos bejaht wurde, hat die zweite eine so einmüthige Beantwortung bis jetzt nicht erfahren. Zu ihrer Entscheidung würden diejenigen drei Punkte in Erwägung zu ziehen sein, welche für die Definition des Erysipels und damit für die Diagnose als entscheidend angesehen zu werden pflegen: 1) die Aetiologie, 2) die pathologische Anatomie, 3) das klinische Krankheitsbild.

Die ätiologischen Verhältnisse des Erysipels schienen zur Zeit, als Massei seine Beobachtungen mittheilte, zweifelsohne festzustehen; eine Opposition, welche die Specifität des Fehleisen'schen Erysipelcoccus bezweifelte, war damals kaum vorhanden oder wurde wenigstens nicht für ernst genommen. Massei durfte also damals mit Fug und Recht behaupten, dass jeder Fall, bei dem eine einwandsfreie, bakteriologische Untersuchung den Fehleisen'schen Streptococcus als Ursache der Erkrankung nachweise, ohne weiteres als Erysipel anzusehen sei. Nun hat er selbst zwar, wie er S. 61 berichtet, keine bakteriologische Prüfung seiner Fälle vorgenommen, seine Arbeit wurde aber nach dieser Richtung hin durch die Mittheilungen von Biondi, Hajek, Samter und Herzfeld ergänzt. Diese fanden bei all' ihren Fällen den Fehleisen'schen Streptococcus; wurde derselbe auch nicht jedesmal in Reincultur gewonnen, so wurde er doch auch niemals vermisst.

Von diesen Arbeiten fallen nun allerdings die beiden letztgenannten in eine Zeit, wo die Opposition gegen die Specifität des Fehleisen'schen Coccus schon sehr erhebliche Dimensionen angenommen hatte, und Massei selbst hatte mittlerweile auf dem X. internationalen Congress zu Berlin in anerkennenswerther Objectivität diesen veränderten Verhältnissen Rechnung getragen, wobei er die volle Zustimmung seiner Correferenten, M. Schmidt und F. Simon, gefunden hatte. Was damals wahrscheinlich war, ist inzwischen immer mehr und mehr zur Gewissheit geworden und die angesehensten Bakteriologen (Baumgarten, C. Fraenkel, E. Fraenkel, Verneuil und Clado, Hell, Mossny, Kirchner, v. Eiselsberg, v. Lingelsheim u. a.m.) vertreten auf Grund vielfacher und sorgsamer Experimente die Anschaung, dass dem Fehleisen'schen Streptococcus keinerlei 
specifische Wirkung zukomme, sondern dass derselbe in seinem ganzen mikroskopischen und biologischen Verhalten mit dem Streptococcus pyogenes Ogoston identisch sei. In den letzten Jahren hat sich meines Wissens kein einziger Forscher in gegentheiligem Sinne geäussert.

Noch verwickelter wurden diese Verhältnisse, als weitere Beobachtungen bekannt gegeben wurden, nach denen gelegentlich auch andere Mikroorganismen ein typisches Erysipel hervorzurufen im Stande sein sollen. So machte Rheiner bei zwei Kranken, die an Typhus abdominalis und gleichzeitig an brandigem Gesichtserysipel litten, den Bacillus typhosus auch für das letztere verantwortlich. Diese Deutung des bakteriologischen Befundes wurde allerdings von Baumgarten und von Fraenkel und Simondi bestritten. Dahingegen scheinen drei andere, von einander unabhängige Mittheilungen, die von Bonome und Uffreduzzi, von M. Jordan und von Felsenthal herrühren, von gewichtigerer Bedeutung zu sein: diese fanden bei der Untersuchung mehrerer typischer Erysipelfälle keine Streptokokken, sondern nur Staphylokokken.

Die Zukunft wird lehren, wie weit die eben mitgetheilten Beobachtungen von anderer Seite bestätigt werden: so viel wird man aber wohl, ohne dieser Entscheidung irgendwie vorgreifen zu wollen, jetzt schon zugestehen müssen, dass die berufensten Forscher auf diesem Gebiete, so viele sich auch mit dieser Frage beschäftigt haben, bei der heutigen Lage der Dinge durchgehend dem Erysipel einen specifischen Erreger absprechen. Diejenigen Autoren also, welche die Diagnose des Larynxerysipels abhängig machen von dem Nachweis eines specifischen Erysipelcoccus - und es sind dahinzielende Bemerkungen noch in Lehrbüchern allerneuesten Datums zu finden -, werden wohl nie in die Lage kommen, diese Diagnose zu stellen. Denn es ist eben, so viel wir bis jetzt wissen, der Fehleisen'sche Coccus von dem Streptococcus pyogenes, den wir in unzähligen phlegmonösen Gewebsentzündungen finden, weder seiner Gestalt, noch seinem Wesen nach zu unterscheiden. Demgemäss sind auch alle bisherigen bakteriologischen Untersuchungen, meine eigenen mit eingeschlossen, von keinem grossen Belang. Selbst das anscheinend entscheidendste Resultat, eine Reincultur von Streptokokken, 
mittelst unanfechtbarer Technik gewonnen - manche der diesbezüglich veröffentlichten Methoden sind übrigens durchaus nicht unanfechtbar - würde bei dem heutigen Stande unseres Wissens für eine Differentialdiagnose zwischen Erysipel und Phlegmone keinerlei Entscheidung bringen.

Meine Versuche, durch Ueberimpfung von StreptokokkenReinculturen irgend welche Schleimhauterkrankungen zu erzielen, sind ziemlich resultatlos geblieben. Vier Mal habe ich eine wässerige Aufschwemmung von Streptokokken verschiedenartiger Provenienz in die Pharynx- oder Larynxschleimhaut verschiedener Thiere eingespritzt. Jedesmal wurde das Ohr eines Kaninchens zur selben Stunde und mit derselben Cultur zur Controle geimpft. Während sich bei den Controlthieren ausnahmslos schon nach 24 Stunden typische Erscheinungen einstellten, zeigten die eigentlichen Versuchsthiere - ein Hund, zwei Katzen, ein Kaninchen - merkwürdigerweise immer nur eine recht unbedeutende Reaction. Die Schwellungen, welche um die Injectionsstelle auftraten, waren so geringfügig und meist so schnell wieder verschwunden, dass selbst die mikroskopische Untersuchung der betreffenden Theile keinerlei nennenswerthe Krankheitsbilder zu Tage förderte ${ }^{1}$ ).

Dahingegen erwies sich eine aus einem Gesichtskarbunkel gewonnene Reincultur von Staphylococcus pyogenes aureus als im höchsten Grade virulent. Mit derselben wurden zwei Katzen geimpft: Katze I erhielt mittelst Pravaz'scher Spritze eine wässerige Aufschwemmung in das Velum palatinum; der Katze II wurde eine entsprechende Dosis unter Spiegelführung in die linksseitige, subglottische Larynxschleimhaut injicirt. Beide Thiere waren schon wenige Stunden nach geschehener Einspritzung offenbar schwer krank; sie sassen still in einer Ecke ihres Käfigs, frassen nicht und vermieden augenscheinlich nach Möglichkeit jede Bewegung des Kopfes. Die an den nächsten Tagen vorgenommene Localuntersuchung ergab folgende Resultate: Bei Katze I zeigte sich der weiche Gaumen etwas verdickt und schwerfällig in seinen Bewegungen; die Schleimhaut war aber nur wenig geröthet. Auch der Larynx hatte seine ursprüngliche

1) Ich bin übrigens weit davon entfernt, diesen negativen Resultaten irgend welche principielle Bedeutung zuzugesteben. 
grauweisse Farbe behalten. Ueber dem linken Aryknorpel war die Schleimhaut stark ödematös durchtränkt. Am folgenden 'Tage war das Velum palatinum noch voluminöser geworden; das Oedem hatte erheblich zugenommen und erstreckte sich über das ganze Lig. ary-epiglotticum bis zum Kehldeckel hin. Bei Katze II war im Pharynx nichts Krankhaftes zu entdecken, hingegen zeigte die linksseitige Umrandung des Aditus laryngis eine hochgradige ödematöse Schwellung, die in den nächsten 24 Stunden auch auf die rechte Kehlkopfseite übergriff. An den ursprünglich erkrankten Partien hatte das Oedem so sehr an Intensität zugenommen, dass die Schleimhaut ballonartig aufgetrieben war. Die Athmung des Thieres war eine äusserst mühsame. Bei beiden Katzen waren die Halsdrüsen stark geschwollen. Am 2. Tage wurden die Thiere getödtet; über den mikroskopischen Befund werde ich später berichten. An dieser Stelle möchte ich nur darauf hinweisen, dass das klinische Bild, das Katze II bis zu ihrem 'Tode zeigte, durchaus nicht vom Erysipel zu unterscheiden gewesen wäre, obgleich dasselbe durch eine Staphylokokkencultur hervorgerufen war: ganz acuter Beginn; die Temperatur war sicher (dieselbe konnte nicht genau festgestellt werden, da die Thiere die Anwendung eines Thermometers nicht duldeten) eine hochfieberhafte; hochgradiges, schnell weiterkriechendes Oedem rings um den Aditus laryngis; laryngeale Dyspnoe und Schmerzhaftigkeit der Halsorgane.

Wir kommen nunmehr zur pathologischen Anatomie des Larynxerysipels. Wenn dieser Name irgend welche Berechtigung haben und nicht geradezu verwirrend wirken soll, so muss man fordern, dass, nachdem sich die Aetiologie als unterscheidendes Moment so wenig stichhaltig erwiesen hat, nun wenigstens die pathologisch-anatomischen Erscheinungen im gegebenen Falle diese Bezeichnung rechtfertigen. Das werden dieselben aber nur dann thun, wenn sie - mutatis mutandis natürlich - sich denjenigen Veränderungen conform zeigen, die man an der äusseren Haut mit dem Namen des Erysipels zu belegen gewohnt ist.

Die patbologisch-anatomischen bezw. mikroskopischen Befunde, die während der letzten Jahrzehnte von hervorragenden Autoren beim Hauterysipel erhoben worden sind, lauten folgen- 
dermaassen: Hebra ${ }^{1}$ ) meint, dass "es sich beim Erysipel wie bei jeder anderen Hautentzündung um Stase und Exsudat handelt. Das Exsudat wird theils in die Cutis selbst, theils zwischen Epidermis und Cutis abgelagert, wodurch die Entstehung von Bläschen, Blasen und Pusteln hinlänglich erklärt wird“. Nach Volkmann und Steudener ${ }^{2}$, deren Angaben die Bisiadeckischen ${ }^{3}$ ) Untersuchungen bestätigen, stellt das Erysipel zwar ursprünglich eine Affection der Cutis dar, aber "auf der Höhe der Erkrankung ist nicht nur diese, sondern auch das subcutane Gewebe so vollkommen durch kleinzelliges Material infiltrirt, dass das mikroskopische Bild des Erysipels sich fast vollkommen mit dem Bilde der bösartigsten Formen acut progredienter Bindegewebseiterungen deckt" (S. 563). Trotz dieser fast vollkommenen Gleichartigkeit der beiden mikroskopischen Bilder suchen unsere Autoren, vorläufig wenigstens, noch eine Scheidung zwischen Erysipel und Phlegmone festzuhalten, so wird (S. 563) „als anatomischer Unterschied des Erysipels von der beginnenden diffusen Bindegewebseiterung die gänzliche Integrität des eigentlichen Parenchyms der Gewebe, das Fehlen des Zerfalls der Fettzellen und der Schmelzung der Intercellularsubstanz" hervorgehoben. Einige Jahre später aber, als Volkmann dasselbe Thema in dem von Pitha und Billroth herausgegebenen Handbuch für Chirurgie bearbeitete vergisst er ganz und gar diese Unterscheidung und verwischt die anatomische Grenzlinie zwischen Erysipel und Phlegmone; S. 137 heisst es: „Auch sind kleine, circumscripte Eiteranhäufungen und selbst diffuse Eiterinfiltrationen, die nicht diagnosticirt und nicht diagnosticirbar bei günstigem Verlauf später symptomlos resorbirt werden, beim Erysipel gewiss ziemlich häufig." Mit diesen Worten soll nicht etwa irgend eine Complication des Erysipels geschildert werden - dann wäre ja gegen dieselben gar nichts einzuwenden sondern die ganze Art der Beschreibung lässt erkennen, dass Volkmann derartige "circumscripte und selbst diffuse Eiterinfiltrationen" als zum Bild des einfachen, uncomplicirten Erysipels gehörig betrachtete. Ganz auf dem Boden dieser Anschauung

1) Virchow's Handb. d. spec. Pathol. u. Therap. 1860. Bd.III. S. 235.

2) Centralbl. f. med. Wissensch. 1868. No. 36.

3) Sitzungsber. d. k. k. Akad. zu Wien. 1867. 
steht die Schilderung, die Küster in der Eulenburg'schen Real-Encyklopädie vom Erysipel entwirft.

Im Gegensatz hierzu wird von Billroth und Winiwarter ${ }^{1}$ ) zwischen Erysipel und Plegmone eine scharfe Grenze gezogen; das anatomische Bild des Erysipels wird (S. 451) folgendermaassen geschildert: "Erweiterung der Capillaren in der Cutis, seröse Exsudation in das Gewebe derselben, lebhafte Entwickelung der Zellen des Rete Malpighii und zellige Infiltration zwischen die Cutisfasern. Auf das Unterhautzellgewebe dehnt sich die Krankheit meist nur in geringerem Maasse aus." Alle stärkeren Infiltrate der Subcutis werden in das Bereich der phlegmonösen Entzündungen verwiesen.

Ziegler ${ }^{2}$ ) wiederum findet , die anatomischen Veränderungen des Erysipels in einer sehr erheblichen, zellig-serösen, mitunter auch zellig-fibrinösen Infiltration der Haut und des subcutanen Bindegewebes". Die mikroskopischen Verhältnisse der Phlegmone werden (S. 426) in ganz entsprechender Weise geschildert, nur ,ist dieselbe durch die Bildung eines eitrig-serösen, oft auch zum Theil eitrig-fibrinösen, zuweilen verjauchenden Exsudats charakterisirt". Ganz anders endlich aber lautet die Schilderung, die Langerhans ${ }^{3}$ ) vom Erysipelas entwirft; nach ihm stellt dasselbe „eine mit heftigem Fieber und mit schweren Allgemeinerscheinungen verbundene, stark entzündliche Schwellung der eigentlichen Haut, mit stark ödematöser und geringerer zelliger Infiltration" dar.

Wie man sieht, ist die Definition des Hauterysipels in pathologisch-anatomischer Beziehung nichts weniger als einheitlich, und die Abgrenzung desselben der Phlegmone gegenüber nichts weniger als feststehend. Der Mangel an Uebereinstimmung, der sich in den eben mitgetheilten Citaten zu erkennen giebt, ist aber ein so auffallender, dass demselben sicher ganz besondere Ursachen zu Grunde liegen müssen. Und ich möchte glauben, dass die Verschiedenartigkeit der Urtheile, die wir eben kennen gelernt haben, zurückzuführen sei auf eine Verschiedenartigkeit der Objecte, die den einzelnen Autoren zur Prüfung vorgelegen

1) Die allgem. chirurg. Pathol. u. Therap. Berlin 1883.

2) Lehrb. d. spec. path. Anat. 1892. II. S. 425.

3) Patholog. Anat. 1891. S. 219. 
haben. Ein reines, uncomplicirtes Erysipel zu untersuchen, mögen wohl nur die wenigsten Gelegenheit gehabt haben; denn derartige Kranke pflegen ja, wenn nicht ganz besondere Zufälle mit im Spiele sind, nicht zu sterben. Diejenigen Erysipelfälle aber, die zur Section und damit zur mikroskopischen Untersuchung kommen, haben gewöhnlich allerhand Complicationen aufzuweisen, so dass sich ein typisches Bild aus denselben kaum gewinnen lässt. Volkmann's Schilderung wenigstens lässt kaum einen $Z$ weifel darüber $z u$, dass bei den drei, einer schweren Erysipelepidemie entstammenden Fällen, die ihm zur Untersuchung vorlagen und aus deren Befunden er seine Schlussfolgerungen zog, das Erysipel durch tiefgreifende phlegmonöse Prozesse complicirt war. Solche Fälle soll man aber nicht als Schulfälle auffassen und aus ihnen darf man keine Definitionen ableiten.

In dem einen Punkte aber sind alle Autoren einig, dass das Erysipel seinen primären und hauptsächlichen Sitz in der Cutis hat, die Phlegmone den ihrigen in der Subcutis. Nur die verschiedenen Uebergangsstadien von der einen Form zur anderen, die sich als mehr oder weniger starke Durchsetzung der Subcutis mit kleinzelligem Material darstellen, die früher sogenannte Infiltratio plastica - diese werden von dem einen dem Erysipel, von dem anderen der Phlegmone zugeschrieben.

Noch verwickelter werden diese Verhältnisse, wenn wir dieselben, wie das nach den vorhergehenden Auseinandersetzungen die Analogie der Namen verlangt, von der äusseren Haut auf die Schleimhaut übertragen. Nach dieser Analogie muss man zuvörderst die Forderung stellen, dass das Larynxerysipel sich als eine Primärerkrankung der eigentlichen Mucosa - denn diese entspricht nach der allgemein üblichen Eintheilung der Cutis an der äusseren Haut - darstellt. Luschka schildert dieselbe (S. 172) als "eine gesetzmässige Bildung von wandelbarer Dicke, die aus kurz- und feinfaseriger Bindesubstanz besteht, in welche zahlreiche Formelemente anderer Art eingestreut sind. Diese Formelemente stellen zart granulirte Körperchen dar, die oft so massenhaft auftreten, dass sie das Fasergerüst der Mucosa fast vollkommen verdecken. Dasselbe wird erst deutlicher in der Submucosa, wo es durchsetzt von spindelför- 
migen Körperchen einen exquisit wellenförmigen Verlauf nimmt." Dieser Schilderung entsprechen vollkommen die Resultate meiner eigenen Untersuchungen; da aber die diesbezügliche Luschka'sche Abbildung (Taf. X, Fig. VI) etwas schematisch gehalten ist, so füge ich die Zeichnung eines eigenen Präparates (Taf. IV, Fig. 1) bei, welches die fraglichen Verhältnisse mit photographischer Treue wiedergiebt. Dieses Präparat lehrt, wie das mitgezeichnete Mikrometermaass und die Vergrösserungstabelle beweisen, dass der Dickendurchmesser der wahren Mucosa etwa 10-12 $\mu$ beträgt. (Der Dickendurchmesser der Cutis beträgt nach Quain-Hoffmann $1-4 \mathrm{~mm}$ ). An den verschiedenen Stellen der Larynxschleimhaut mag die Mucosa etwas mehr oder weniger breit angeordnet sein, die absoluten Werthe derselben sind aber durchgehends äusserst geringe. Des ferneren sieht man, dass die Strukturverhältnisse der Mucosa von denen der Submucosa nur in sehr geringem Maasse abweichen, während doch Cutis und Subeutanea recht handgreifliche Unterschiede in ihrem Aufbau zeigen. In Folge dessen ist auch der Uebergang von der einen zu der anderen Schicht bei der Schleimhaut der denkbar allmählichste. Ich könnte nirgends, wie das in der Luschka'schen Abbildung angedeutet ist, eine bestimmte Grenzlinie fixiren: die granulirten Formelemente werden nach der Tiefe zu seltener; das Fasergerüst, welches unmittelbar unter der Epithelschicht gewöhnlich parallel zur Oberfläche verläuft, wird allmählich lockerer und spaltet sich bald bier, bald dort, um in der Tiefe Drüsen und Muskelbündel zwischen seine Züge aufzunehmen.

Mit dieser Anordnung des Fasergerüstes geht diejenige der hierher gehörigen Lymphbahnen Hand in Hand. Nach Teichmann (s. Luschka, S. $153 \mathrm{ff}$.) lassen dieselben an manchen Stellen, so an der oberen Umrandung des Kehlkopfes, eine zweifache Schicht erkennen, von denen die eine der Mucosa, die andere der Submucosa entspricht. An anderen Partien aber, beispielsweise an den Taschenbändern, finden so zahlreiche Communicationen der Lymphwege unter einander statt, dass eine Trennung in zwei Lagen nicht mehr durchführbar ist.

Unter solchen Verhältnissen liegt natürlich auch bei jeder leichten Affection der Schleimhautoberfläche eine gewisse Gefahr 
vor, dass die tieferen Gewebspartien in den pathologischen Prozess mit hineingezogen werden. Und zwar ist diese Gefahr bei der Larynxschleimhaut, dank der eben geschilderten anatomischen Anordnung derselben, noch viel grösser als bei der äusseren Haut, wo ja auch schon ein Uebergreifen der Erkrankung von einer Schicht zur anderen keine Seltenheit ist. Hier wie dort ist es aber, wie wir gesehen haben, die Mitbetheiligung gerade dieser Partien, welche einer einheitlichen Deutung and Auffassung der in Frage stehenden Prozesse am meisten im Wege steht. Mag deshalb Massei auch formell in seinem guten Recht gewesen sein, als er bei der nun einmal bestehenden Unsicherheit der Krankheitsbestimmungen die Volkmann'sche Definition seinem primären Larynxerysipel zu Grunde legte, zweckmässig war die Annahme gerade dieser Principien mit ihren weitgehendsten Folgerungen für eine einheitliche und übersichtliche Klassificirung aller hierher gehörigen Affectionen gewiss nicht. Ausserdem meine ich, dass gerade jetzt, wo man allgemein bemüht ist, das Erysipel und die acute infectiöse Phlegmone von einem übergeordneten Gesichtspunkt aus zusammenzufassen, mehr noch als vordem die Nothwendigkeit vorliegt, die Grenze zwischen den beiden zusammen gehörigen, aber doch nicht vollkommen identischen Erkrankungen festzuhalten. Denn darüber kommen wir doch nicht hinweg, dass Erysipel und Phlegmone trotz all' ihrer nahen Beziehungen zu einander immer noch zwei recht verschiedenartige Prozesse darstellen. Ein Schulfall von Larynxerysipel im Sinne von Hebra, Billroth, Langerhans würde jedenfalls auf Grund Massei'scher Anschauungen kaum zu diagnosticiren sein; denn ein Infiltrat, das in seinem wesentlichen Theil der Mucosa angebört, würde bei dem minimalen Dickendurchmesser dieser nur so geringfügige Veränderungen in den Contouren des Kehlkopfes hervorrufen, dass dieselben bei einer Spiegeluntersuchung kaum wesentlich in's Auge fallen dürften. Andererseits würde, selbst wenn man solche Fälle, wo es (wie bei dem X. Fall von Massei) zu offenkundigem Eiterdurchbruch kommt, aus der Reihe der Erysipelerkrankungen streicht, das Gebiet der phlegmonösen Erkrankungen immer noch zu eng gefasst sein. Müsste man doch die grosse Reihe der Uebergangsformen - die Infiltrationes plasticae - 
immer noch zum Erysipel rechnen, obgleich dieselben in Folge der überwiegenden Erkrankung der Submucosa anatomisch der Phlegmone viel näher stehen als dem Erysipel. Und wo soll man die Fälle unterbringen, bei denen unter diesem derben Infiltrate in der Tiefe sich „undiagnosticirte und undiagnosticirbare Eiteransammlungen" verbergen? Kein Autor, mit Ausnahme von Volkmann, geht, wie wir gesehen haben, so weit, ein derartiges Krankheitsbild als typisches Erysipel anzusprechen.

Aus diesen Gründen, glaube ich, würde man gut thun, wollte man sich bei der anatomischen Begriffsbestimmung des Larynxerysipels an ein Wort Virchow's halten, der ja schon oft genug auch unserer Fachwissenschaft die Wege geebnet hat. „Das Larynxerysipel“, meinte er bei einer diesbezüglichen Discussion ${ }^{1}$ ), „macht anatomisch nicht viel anderes als eine ödematöse Anschwellung. " Eine Stütze findet diese Anschauung darin, dass auch an der äusseren Haut überall da, wo sich dieselbe durch die Verdünnung der Cutis and die lockere Anordnung der Subcutanea dem Aufbau der Schleimhaut nähert, so z. B. an den Augenlidern und am Präputium, ein eventuelles Erysipel sich viel weniger durch körperliches Infiltrat als durch ödematöse Schwellung zu erkennen giebt; eine fernere Stütze sehe ich darin, dass, wie Eppinger nachgewiesen hat (S. 66) und meine Abbildung (Taf. IV, Fig. 2) bestätigt, bei acuten Oedemen der Larynxschleimhaut, welcher Aetiologie sie auch immer ihr Entstehen verdanken, überhaupt kein kleinzelliges Infiltrat aufzutreten pflegt. Die Abbildung illustrirt die anatomischen Veränderungen, die sich in dem Kehlkopf jener Katze II vorgefunden haben, deren Krankengeschichte ich weiter oben schon mitgetheilt habe. Trotz des hochgradigen, bereits in Zerfall begriffenen Infiltrats in der Tiefe der Gewebe sind die Oberflächenpartien, die in vivo die ausgebreitetsten Oedeme zeigten, von jedem zelligen Infiltrat vollkommen freigeblieben.

An Fällen, die als Paradigmata für diese strengere Auffassung des Larynxerysipels dienen können, fehlt es nicht; ich finde dieselben in den Mittheilungen von Bergmann's, Ziegler's, und Herzfeld's. In all' den von diesen Autoren mitgetheilten Krankheitsbildern stossen wir auf dieselben Symptome, die

') Verbandl. der Berl, med. Gesellsch. 1887. I. S. 80 , 
Massei als charakteristisch für das klinische Bild des Larynxerysipels bezeichnet hat. Das anatomische Substrat aber wird immer und allein geliefert durch die ödematöse Schwellung der Kehlkopfschleimhaut. Die rapide Schnelligkeit, mit welcher dieselbe entsteht, von einem Ort zum anderen weiterkriecht and schliesslich auch verschwindet, scheint mir dem Bilde des Erysipels viel mehr zu entsprechen, als das seiner ganzen Natur nach schwerfälligere, körperliche Infiltrat, welches für das Bild der Phlegmone charakteristisch ist; auch diese wandert ja, wie wir wissen, aber es fehlt ihr die flüchtige, von Ort zu Ort huschende Art, welche das Erysipel auszeichnet und welche man bei dem bestens beobachteten Ziegler'schen Fall in so prägnanter Weise ausgeprägt findet.

Nur noch eine einzige Schwierigkeit, welche diese Auffassung mit sich bringt, bleibt zu überwinden: Ich habe von Anfang an darauf hingewiesen, dass der Name "Larynxerysipel“" nur dann eine Berechtigung hat, wenn es sich in Analogie zum Hauterysipel um eine primäre Erkrankung der eigentlichen Mucosa handelt - das Oedem aber, das ich als einziges anatomisches Substrat für diese Diagnose heranziehen möchte, wird gemeiniglich als eine Affection der Submucosa aufgefasst. Hierzu ist nun zu bemerken, dass diese Ansicht trotz der allgemeinen Anerkennung, die sie bis jetzt gefunden hat, in solch uneingeschränkter Form nicht zutreffend ist. Zuvörderst liegt es auf der Hand, dass bei Oedemen, die z. B. durch Verbrennung oder Einkeilung von Fremdkörpern im Larynx hervorgerufen werden, das schädigende Agens seine reizende Wirkung zu allererst und zwar mit vollster Wucht, auf die oberflächlichen Schichten, also auf das Epithel ond auf die Mucosa, ausgeübt haben muss, bevor dieselbe bis zu den tieferen Lagen der Submucosa durchdringen kann. Bei derartig schweren Traumen wird man nun allerdings den Einwand erheben können, dass, wenn auch Epithel und Mucosa den ersten Anprall auszuhalten haben, die Energie der Noxe doch stark genug ist, um auch noch die Submucosa augenblicklich in einen schweren Entzündungszustand zu versetzen. Es giebt aber gewisse Fälle von Larynxödem, bei denen dieser Einwand sich nicht aufrecht erhalten lässt, so z. B. dort, wo durch sonst ganz harmlose Pinse- 
lungen mit Höllensteinlösungen ein Oedem der Kehlkopfschleimhaut hervorgerufen wird. Derartige Beobachtungen - und dieselben sind ja durchaus nicht vereinzelt - weisen doch mit einem hohen Grade von Wahrscheinlichkeit darauf hin, dass unter Umständen auch ein Reiz, der nur die Oberfläche der Schleimhaut trifft, genügt, um ein Oedem auszulösen. Wissen wir doch, dass gerade das Argentum nitricum in seiner Wirkung auf die Gewebe auf die Oberfläche beschränkt ist, und in Folge dessen sind wir, glaube ich, zu der Annahme berechtigt, dass diejenige Veränderung der Gefässwände, die zum Zustandekommen eines serösen Transsudats nothwendig ist, durch das Argentum nitricum unmittelbar nur in den oberflächlichen Lagen der Schleimhaut ausgelöst wird. Selbstverständlich wird die Alteration der Gefässwände nicht an der Grenze zwischen Mucosa und Submucosa Halt machen, sondern mehr oder weniger auch in das Gebiet der letzteren hinüberreichen, aber die Provenienz der transsudirten Flüssigkeit weist in allererster Reihe auf die Gefässe der Mucosa hin. Wir müssen uns bei diesen Ueberlegungen durch erfahrungsgemässe Schätzungen leiten lassen; ein mathematischer Beweis, wie weit diese oder jene Schädlichkeit ihre selbstthätige Wirkung ausdehnt, lässt sich eben nicht erbringen. Mit Sicherheit beweisen lässt sich hingegen, dass acut entzündliche Oedeme gegebenen Falles nicht nur die Submucosa, sondern auch die Mucosa durchsetzen und bis an die oft in Blasenform abgehobene Epithelschicht heranreichen.

Ich habe, um diese Verhältnisse zu studiren, zwei narkotisirten Hunden kochendes Wasser und Crotonöl in den Kehlkopf eingespritzt. Sobald sich Oedeme zeigen, wurde die Narkose bis zum Exitus lethalis gesteigert und die sofort herausgenommenen Kehlköpfe in kochendem Wasser oder überschüssiger Sublimatlösung fixirt. Bei den auf diese Weise vorbereiteten Präparaten zeigte sich das Epithel hier und dort blasenartig von seiner Unterlage abgehoben; die Faserbündel der Mucosa und der Submucosa, waren durch eine schwach gelblich gefärbte - wahrscheinlich ist diese Färbung durch das Mitaustreten von rothen Blutkörperchen in's Gewebe bedingt - keinerlei Tinction annehmende Masse aus einander gedrängt; zellige Infiltration aber war nirgends $z u$ sehen. 
Wenn ich trotz dieser Erwägungen an der Auffassung, welche das Larynxödem als eine submucöse Affection hinstellt, nicht rütteln will, so geschieht das aus dem Grunde, weil der Schwerpunkt aller in's Auge fallenden Veränderungen in der That immer in der Submucosa zu suchen ist, ganz gleich ob dieselbe activ oder nur passiv in Mitleidenschaft gezogen ist. Denn die Mucosa kommt, so lange es sich um solch grobe Verhältnisse handelt, wegen ihrer geringen Dickenausdehnung für das seröse Transsudat eben so wenig in Betracht als für die kleinzellige Infiltration. Es kam mir einzig und allein darauf an, nachzuweisen, dass die Auffassung, nach welcher das Oedem das einzig anatomische Substrat des Larynxerysipels darstellt, keinen logischen Widerspruch gegen die enger und schärfer begrenzte Definition Hebra's, Billroth's und Langerhans' in sich schliesst, und dass dieses anatomische Substrat für die Diagnose eines Erysipels durchaus genügt; an der Larynxschleimhaut eben so gut wie am Präputium und den Augenlidern.

Dem klinischen Krankheitsbilde, wie es von Massei formulirt ist, habe ich nichts hinzuzufügen.

Ich erkenne also die Massei'sche Entdeckung in ihrer hohen Bedeutung voll und ganz an, halte es aber für dringend wünschenswerth, dass die anatomischen Verhältnisse des Larynxerysipels etwas schärfer präcisirt werden. Felix Semon hat sich einmal (Internat. Centralbl. für Laryngologie. 1893. Bd. X. S. 55) dahin ausgesprochen, dass "seiner Ueberzeugung nach das entzündliche Oedem des Kehlkopfes, die sogenannte phlegmonöse Laryngitis, das Erysipel des Larynx und die Ludwig'sche Angina mit einander identisch seien und nur verschiedene Abstufungen ein und desselben Prozesses darstellen“. Wenn ich diese Worte dahin deuten darf, dass die "Identität" der betreffenden Erkrankungen sich auf ihre Aetiologie und ihre Wesenheit als acute Infectionskrankheiten bezieht und dass mit "der verschiedenen Abstufung ein und desselben Prozesses" die Verschiedenartigkeit des pathologisch-anatomischen Bildes und die hieraus resultirende Abweichung der klinischen Erscheinungen und der Prognose bezeichnet werden soll, so kann ich denselben rückhaltlos beistimmen.

Da aber jeder einzige der eben angeführten Pro- 
zesse selbständig für sich allein in die Erscheinung treten kann, so müssen wir auch für jeden einzelnen derselben die eigenen Grenzwerthe finden, wodurch eine Zusammenfassung aller hierhergehörigen Erscheinungen unter einen übergeordneten Begriff durchaus nicht gefährdet wird.

Wenn wir aber, wie das von autoritativer Seite geschehen ist, das "Larynxerysipel kurzweg als eine phlegmonöse Laryngitis bei bestehendem Genius epidemicus" bezeichnen, so verwischen wir diejenige Grenzlinie, die wir innezuhalten verpflichtet sind, und es bleibt jener Vorwurf zu Recht bestehen, den v. Bergmann ${ }^{1}$ ) vor etwa $7-8$ Jahren gegen uns erhoben hat, dass man in der Laryngologie ,als eine Capitelüberschrift Oedema laryngis und phlegmonöse Entzündung unbeanstandet neben einander gestellt findet, während man bei jedem anderen Körpertheil sich gegen eine derartige Zusammenstellung wenden würde".

Deshalb schlage ich vor, unter dem Namen des primären Larynxerysipels nur diejenigen Fälle zu begreifen, bei welchen das Oedem bei gegebenem klinischem Krankheitsbild, das die Situation beherrschende, local anatomische Substrat bildet. All' die übrigen Erkrankungen, bei denen sich unter sonst gleichen Bedingungen ein körperliches Infiltrat in überwiegender Weise geltend macht, mögen als acut infectiöse Phlegmonen aufgefasst werden. Will man aber diesen Namen nur für jene Fälle reserviren, wo es zu einer manifesten, eitrigen Schmelzung des Gewebes kommt, so mag man die Uebergangsstadien nach altem Muster als plastische Infiltrationen bezeichnen.

Bis jetzt hat man immer die Fiebercurve als maassgebend für die Differentialdiagnose zwischen Erysipel und Phlegmone angesehen: wie wenig diese für diesen $Z$ weck genügt, und wie nothwendig eine Scheidung auf ànderer Basis ist, das kann nicht schlagender bewiesen werden, als durch jene Discussion zwischen Senator und Guttmann über die acute infectiöse Phlegmone des Pharynx, die am 18. Januar 1888 in der Berliner Medicinischen Gesellschaft statthatte. Senator war der Meinung, er proclamire in seinem Vortrage ein neues Krankheitsbild. Demgegenüber betonte Gutt-

1) v. Bergmann, Deber primäres Larynxerysipel. Petersb. med. Wochensehrift. 1887. No. 49,50 . 
mann, dass die von dem Vortragenden geschilderte Affection schon lange bekannt und auch des Oefteren unter dem Namen "Schleimhanterysipe]" beschrieben sei. Diese Auffassung wurde mit Entschiedenheit zurückgewiesen: von einem Schleimhauterysipel, sagte Senator, dürfe man doch nur dann sprechen, wenn durch den Nachweis Fehleisen'scher Erysipelkokken oder durch ein voraufgegangenes, bezw. nachfolgendes Hauterysipel die Natur der vorliegenden Erkrankung zweifelsohne sicher gestellt sei. Die Untersuchungen der nächsten Jahre haben nun zwar gelehrt, dass selbst diese Kriterien, die Seuator damals als unbedingt entscheidende ansah, einer genaueren Prüfung nicht Stand halten; in einem Punkte aber war der Vortragende in seinem guten Recht: er durfte die Auffassung als eine willkürliche bezeichnen, welche eine tiefgreifende, diffuse Eiterung ohne Weiteres in die Kategorie der erysipelatösen Erkrankungen rechnet. Mag man auch früherhin schon ähnliche Fälle gesehen und beschrieben haben, die anatomischen Verhältnisse derselben hatte man nicht genügend in Betracht gezogen, und durch diesen Mangel war eine Unklarbeit in der Terminologie und in der Auffassung bedingt worden, welche $z$ wei hervorragende Kliniker in einer ausgedehnten, mündlichen l)iscussion nicht einmal darüber einig werden liess, ob sie überhaupt von ein and derselben Sache oder verschiedenartigen Dingen sprächen. All' die Fälle, die nach Aufstellung des Senator'schen Paradigmas von Landgraf, Baruch, Germonig, Schäffer u. A. m. mitgetheilt wurden, rechtfertigen ebenso wie dieses selbst die anatomische Diagnose der infectiösen Phlegmone voll und ganz; ihr klinischer Theil aber, und das scheint mir vou wesentlicher Bedeutung, deckt sich fast vollkommen mit dem Krankheitsbilde, das Massei vom primären Larynxerysipel entworfen hat. Beide Erkrankungen setzen ganz plötzlich, meist mit Schüttelfrost, ein; das Fieber erreicht des Abends, besonders in den ersten Tagen, eine ziemlich beträchtliche Höhe $\left(39-40^{\circ}\right)$, die Morgentemperaturen pflegen um $0,5-1,0^{\circ}$ niedriger zu sein. Hier wie dort zeigen die Halsorgane schon während der Ruhe und noch vielmehr während des Schluckens grosse Schmerzhaftigkeit. Die Athmung ist erschwert 
und der Patient in beiden Fällen auffallend matt und hinfällig. Nur die Localuntersuchung der erkrankten Partien lässt einige Unterschiede erkennen. Die Rachengebilde, die bei der Massei'schen Affection gar nicht oder nur durch das Uebergreifen des Oedems von Larynx auf den Pharynx betheiligt sind, zeigen bei der Phlegmone derbe Schwellungen und starke Röthungen, die durch tiefsitzende, diffuse Eiterungen bedingt sind. Am Kehlkopf selbst sieht man beim Erysipel, meiner früheren Auseinandersetzung gemäss, nur Röthung und Oedeme, bei der Phlegmone ist die Schleimhaut zwar auch geröthet, aber dieselbe nimmt, besonders, wenn die Affection eine Zeit lang andauert, oft einen verwaschenen, grauröthlichen Farbenton an. Alle nor. malen Contouren sind durch derbe, ungefügige Schwellungen, denen unter Umständen auch hier und da ein circumscriptes Oedem sich zugesellen kann, verwischt. Ebenso wie die Phlegmone der Haut zeigt auch die Phlegmone der Schleimhaut die Tendenz, von einem Punkt zum anderen weiter zu kriechen; aber ihre Bewegung ist langsam und schwerfällig beim Kommen sowohl wie beim Gehen und hat nichts von der charakteristischen Flüchtigkeit des erysipelatösen Oedems. Beiden Erkrankungen gemeinsam ist ferner das Auftreten der sogenannten "Phlyctänenbildung". Dieselben stellen membranartige, weisse oder weissgraue Belege dar, an deren Stelle, wenn sie vorzeitig losgelöst werden, oberflächliche Substanzverluste zu Tage treten. Für gewöhnlich aber fallen diese Pseudomembranen erst ab, wenn die Schleimhaut unter denselben vollständig regenerirt ist. Narbenbildung an den betreffenden Stellen habe ich nicht beobachtet, obgleich, wie die mit dem Zeichenspiegel gezeichnete Abbildung No. 3 beweist, dieser Prozess manchmal recht tief greift. Unter dem Mikroskop erkennt man - in Fall VIII und XI hatte ich Gelegenheit, diese Verhältnisse zu untersuchen - dass es sich bei diesen "Phlyctänen" um ein fibrinöses Trans- und Exsudat handelt, bei dem es auch zu einer Nekrose des Epithels und der obersten Schichten des subepithelialen Gewebes kommen kann (s. Fig. 3). Diese fibrinöse Exsudation hat meines Erachtens gar nichts Charakteristisches an sich, denn wir wissen, dass alle möglichen Schleimhäute des Athmungs- und Verdauungstractus auf sehr viele Entzündungsreize in dieser Weise reagiren und ich 
glaube, es wird vergebliche Mühe sein, diese Dinge in ein gemeinschaftliches, etwa bakteriologisches System bringen zu wollen. Zeigen doch die mit fibrinösen Belägen einhergehenden Schleimhautentzündungen bei der Influenza, beim Typhus, bei der Rhinitis und Enteritis fibrinosa genau dasselbe anatomische Bild, wie ich es eben für die Phlegmone und das Erysipel geschildert habe.

Von all' den Fällen, die unter der Diagnose der acuten infectiösen Phlegmone des Pharynx mitgetheilt worden sind, habe ich nur gegen zwei einen Einwand zu erheben. Während sich nehmlich in dem Senator'schen Paradigma überall eine thatsächliche, schwere Erkrankung der Pharynxschleimhaut vorfindet, bemerkt Schäffer in seiner Mittheilung, "die Tonsillen und die Schleimhaut der hinteren Pharynxwand sind nur wenig geröthet, nicht geschwellt". Im Sectionsprotocoll, das eine zweifellos phlegmonöse Erkrankung der Epiglottis, der Lig. ary-epiglottica und der beiderseitigen Sinus pyriformes angiebt, geschieht der Rachengebilde überhaupt keine Erwähnung, was ich wohl in Gemeinschaft mit dem in vivo erhobenen Befund dahin deuten darf, dass sich hier keine nennenswerthe Erkrankung vorgefunden hat. In der Baruch'schen Publication lesen wir: "Die Schleimhaut des Rachens ist eher blass, als geröthet, nicht geschwollen". Der Larynx hingegen zeigte auch in diesem Falle eine unbestreitbare Phlegmone. Es will mir nun nicht einleuchten, weshalb man auch in diesen Fällen durchaus eine Pharynx-Phlegmone annehmen soll, obgleich der Pharynx keinerlei Krankheitserscheinungen aufzuweisen hätte. Wäre es nicht viel einfacher und naturgemässer, diese Fälle als acute infectiöse Phlegmonen des Larynx aufzufassen, da der Larynx allein afficirt war und doch der Eingangspforten für Infectionskeime gerade genug bietet?

Der Baruch'sche Fall bildet übrigens einen guten Beleg für die Ansicht, dass Erysipel und acute infectiöse Phlegmone nur Abstufungen ein und desselben Krankheitsprozesses darstellen: Ein 58jähriger Mann erkrankt, nachdem or Tage lang zuvor seinen an Erysipelas facieis leidenden Sohn gepflegt hat, unter ganz stürmischen Erscheinungen, die auf Grund der Anamnese, des klinischen Bildes und des localen Befundes ("der Kehldeckel und die Stimmbänder erscheinen wie gequollen, glasig, ödematös") wohl allseitig als primäres Larynxerysipel 
gedeutet worden wären. Ein hinzutretendes Hauterysipel kann diese Diagnose nur bekräftigen; aber der Eiter, der sich bei der Ausführung der nothwendig gewordenen Tracheotomie aus dem Larynxgewebe entleerte, beweist, dass das im Anfang wahrscheinlich reine Erysipel durch eine tiefe, phlegmonöse Erkrankung complicirt worden war.

All' diese Fälle, die bis jetzt als acut infectiöse Phlegmonen veröffentlicht wurden, haben einen tödtlichen Verlauf genommen, und zwar trat der Tod gewöhnlich nicht auf der Höhe der Localerkrankung, auch nicht in Folge einer greifbaren Nacherkrankung ein, sondern die meisten Patienten starben in ganz eigenthümlicher Weise unter adynamischen Erscheinungen, oft genug gerade in dem Augenblick, wo eine unverkennbare Besserung des localen Leidens die Hoffunng auf vollkommene Genesung gerechtfertig erscheinen liess. Es liegt der Gedanke nahe, dass hier wie bei vielen anderen septischen Affectionen die Hauptgefahr nicht sowohl in der localen Erkrankung, als vielmehr in der durch die Allgemeininfection bedingten Herzschwäche zu sehen ist. Uebrigens bin ich durchaus nicht der Mejnung, dass jede acut infectiöse Phlegmone des Pharynx oder Larynx tödtlich endigen muss; wahrscheinlich hat man gemeint, die Diagnose stimme nicht, wenn die Patienten mit dem Leben davon kämen, und hat deshalb die Mittheilung solcher Fälle vernachlässigt. Ich wüsste wenigstens nicht, wie ich die Fälle I, II, IV, $\mathrm{V}$, die doch alle wieder gesund geworden sind, anders als acut infectiöse Phlegmonen deuten sollte; Fall VIII und IX sind als solche durch die Section und die mikroskopische Untersuchung $\mathrm{zweifelsohne} \mathrm{sicher} \mathrm{gestellt.} \mathrm{Viel} \mathrm{günstiger} \mathrm{als} \mathrm{hier} \mathrm{aber} \mathrm{liegen}$ jedenfalls die Verhältnisse beim primären Larynxerysipel. Selbst wenn ich alle Fälle, die unter dieser Diagnose veröffentlicht wurden, hier in Betracht ziehe, so dürften es allerhöchstens 25 bis 30 pCt. sein, die einen unglücklichen Ausgang nahmon. Die crste und hauptsächlichste Gefahr liegt beim Erysipel, gerade im Gegensatz zur Phlegmone, in der Localerkrankung des Kehlkopfes, welche durch die rapide Schnelligkeit, mit der sich die ausgedehntesten Oedeme zu entwickeln pflegen, leicht zur Erstickung führen kann. Und diese Gefahr besteht nicht nur im Anfang der Erkrankung, sondern sie kann immer wieder, so lange noch eine Spur des Krankheitsprozesses vorhanden ist, Archiv f. pathol. Anat. Bd.139. Hft.1. 


\section{6}

durch einen plötzlichen Nachschub oder gar durch ein Recidiv bedingt werden. Neben der Erstickungsgefahr, die beim Larynxerysipel jedenfalls als die hauptsächlichste zu betrachten ist, sind es des öfteren entzündliche Lungenaffectionen, die das Leben des Kranken bedrohen. Diesen kann neben manchen anderen ursächlichen Momenten auch ein Uebergreifen des erysipelatösen Prozesses auf das Lungengewebe zu Grunde liegen. Doch muss man mit der Diagnose der erysipelatösen Pneumonie, wie die Mittheilungen Hajek's gezeigt haben, etwas vorsichtig sein. Dieser untersuchte zwei Fälle, bei denen typische Haupterysipele durch den Hinzutritt tödtlicher Pneumonien complicirt wurden. Nur in einem Falle lag beiden Affectionen der gleiche Mikroorganismus (Streptokokken) zu Grunde, bei dem anderen Kranken war die Hautaffection, die noch dazu Thorax und Rücken ergriffen hatte, durch Streptokokken, die Lungenaffection aber durch den Diplococcus pneumoniae Fraenkel verursacht. Dass der Tod, wie bei der Phlegmone, unter adynamischen Erscheinungen nach Ablauf der Localerkrankung sozusagen als Herzparalyse auftritt, scheint beim uncomplicirten Larynxerysipel kaum vorzukommen.

Erysipel und infectiöse Phlegmone des Larynx sind also nach dem heutigen Stande unseres Wissens nicht unterscheidbar nach ihrer Aetiologie. Das klinische Bild beider Affectionen ist oft zum Verwechseln ähnlich. Dahingegen zeigt die Localuntersuchung und der Verlauf der Erkrankungen gewisse Differenzen, und ebenso bietet die pathologische Anatomie, welche für die eine Erkrankungsform ein seröses Transsudat, für die andere ein kleinzelliges oder eitriges Infiltrat als maassgebendes Substrat nachweist, eine ausreichende Handhabe, um die beiden Prozesse von einander zu unterscheiden und die Aufstellung von typischen Bildern zu ermöglichen. Die unzäbligen Uebergänge zwischen den beiden Erkrankungsformen und ihre gemeinschaftliche Aetiologie legen den Gedanken nahe, dieselben als Abstufungen ein und desselben Prozesses zu betrachten.

Wir verlassen nunmehr das Gebiet der Infectionskrankheiten und wenden uns denjenigen Affectionen zu, die in den neuesten Lehrbüchern unter dem Titel des Larynxödem, der submucösen und der phlegmonösen Entzïndung behandelt zu werden pflegen.

Da müssen wir zuvörderst die Frage aufwerfen: Haben wir 
ïberhaupt das Recht, ein eigenes Krankheitsbild unter dem Namen "Larynxödem" aufzustellen? Die Geschichte des Larynxödems hat gelehrt, dass die Beantwortung, welche diese Frage im Laufe der Zeiten erfahren hat, nichts weniger als eine einheitliche gewesen ist. Bouillaud, Cruveilhier und Bricheteau haben dieselbe rundweg verneint; das Oedem, das bei den verschiedensten Kehlkopferkrankungen auftreten kann, stellt nach ihnen keine principielle, sondern nur eine roin consecutive Erscheinung dar, deren ganzes Wesen höchst wechselvoller Art ist: das seröse Transsudat von heut kann sich morgen als plastisches und übermorgen als eitriges Infiltrat präsentiren. Ein solch' schwankendes Symptom aber, meinten sie, dürfe für eine grosse Gruppe von Affectionen, die in ihrer Aetiologie und in ihrem Verlauf die allererheblichsten Verschiedenheiten aufzuweisen haben, bei der Namengebung nicht den entscheidenden Factor ausmachen.

Diese Anschauungen enthalten zweifelsohne viel Wahres, aber unseren Autoren ist es entgangen, dass es eine Anzahl von Erkrankungen giebt, bei denen das seröse Transsudat des Kehlkopfes eine durchaus bleibende Erscheinung darstellt, die ohne Hinzutritt neuer Schädlichkeiten ihren Charakter in keiner Weise ändert. Das sind die von Sestier und Friedreich sogenannten Fälle von einfachem und von passivem Oedem. Hierzu zählten sie die hydropischen Ergüsse, die durch Anämie and Kachexie, durch Blut-, Herz- and Nierenerkrankungen und durch venöse Stauungen hervorgerufen werden. Vielleicht sind an dieser Stelle noch einige Formen des Larynxödems einzureihen, deren Wesenheit erst in späterer Zeit klargestellt worden ist, ich meine das angio-neurotische und das Jodödem. Es ist aber bis jetzt ein vollkommenes Einvernehmen, ob es sich bei diesen Affectionen um localentzündliche Vorgänge handelt oder nicht, noch nicht erzielt. Von dieser Entscheidung wird es abhängen, an welcher Stelle diese Fälle endgültig unterzubringen sein werden.

Bei all' diesen Erkrankungen, so verschieden auch immerhin ihre Aetiologie sein mag, ist das seröse Transsudat in seiner wesentlichen Erscheinung immer dasselbe und ohne Hinzutritt neuer, anders gearteter Schädlichkeiten verändert dasselbe seine Natur nicht: es stellt also für diese Fälle ein constantes Symp- 
tom dar. Des ferneren haben diese Erkrankungen das Gemeinsame, dass bei ihnen dem Kehlkopf jeder active Reizzustand durchaus fehlt. Die Alteration der Gefässwandungen des Larynx, ohne welche ein Oedem nun einmal nicht zu Stande kommen kann, wird hier nicht durch eine Localerkrankung bedingt; ganz andere fernliegende Organe tragen die Schuld hieran und der Kehlkopf selbst bildet für den hydropischen Erguss nur eine rein passive Ablagerungsstätte, gerade so wie das Unterhautzellgewebe für das analoge Hautödem. Man könnte einwenden, dass unter solchen Verhältnissen das Oedem des Larynx auch eben so wenig eine besondere Stellung in der Pathologie beansprachen dürfe, wie das Oedem des Unterhautzellgewebes. Aber ich glaube, dass die hohe Lebenswichtigkeit, die dem Kehlkopf doch nun einmal zukommt, und die grosse Gefahr, die durch das Auftreten eines Oedems in demselben bedingt wird, immerhin die Aufstellung eines besonderen Krankheitsbildes rechtfertigen. Wird doch auch der Hydrops des Pericards und der Hirnventrikel an besonderer Stelle besprochen.

Für diese nicht entzündlichen Fälle möchte ich den Namen "Larynxödem" beibehalten wissen; denn das seröse Transsudat stellt in diesen Fällen, wie gesagt, keine wechselnde, sondern eine constante Erscheinung dar: es repräsentirt das einzige Moment, das diesen Erkrankungen gemeinschaftlich ist.

Für alle Arten des sog. entzündlichen Oedems hingegen gilt mit vollem Recht jener Einwand Bouillaud's, Cruveil hier's und Bricheteau's: eine Erscheinung von so veränderlicher Art, die von Stunde zu Stunde ihre Wesenheit wandeln kann, darf nicht zum Eintheilungsprincip für eine so wichtige und umfassende Gruppe von Erkrankungen erhoben werden. Denn in ihren pathologisch-anatomischen Verhältnissen zeigen die Fälle, die bisher in die Rubrik des entzündlichen Oedems gerechnet wurden, genau dasselbe wechselvolle Bild and dieselben Stadien, die wir bei den acut infectiösen Larynxerkrankungen kennen gelernt haben. Aber hier wie dort sind die einzelnen Krankheitsbilder, das Oedem, das plastische und das eitrige Infiltrat, durch Uebergänge, die in unmerklicher Weise von dem einen zum anderen führen, verbunden, so dass dieselben wieder trotz all' ihrer Verschiedenartigkeit als Abstufungen ein und desselben Krank- 
heitsprozesses erscheinen, die, wenn es der Zufall will, an ein und demselben Patienten der Reihe nach zur Beobachtung kommen können. Ein Fremdkörper z. B., der in das Kehlkopfinnere eindringt, kann dort, manchmal binnen wenigen Minuten, ein ausgebreitetes Oedem entzündlicher Natur hervorrufen. Wenn in diesem Stadium die Entfernung des gefährlichen Eindringlings aus irgend einem Grunde unterbleibt und der Patient, etwa durch die Tracheotomie, vor dem Suffocationstode bewahrt bleibt, so kann sich, dank der immer tiefer greifenden Reizung des Gewebes, zu dem ursprünglich rein serösen Transsudat bald eine grosse Menge kleinzelligen Infiltrationsmaterials hinzugesellen - Stadium plasticum —, und dieses wird in dem Augenblick, wo die Anhäufung von Rundzellen eine weitere Ernährung der Gewebe unmöglich macht, zum eitrigen Zerfall führen.

Wir können hier die Frage, ob der mechanische Insult allein genügt, um eine Eiterung hervorzurufen, oder ob dazu die Mitwirkung irgend welcher. Infectionskeime nothwendig ist, als für unsere Betrachtung unwesentlich bei Seite lassen. Denn selbst wenn man den letzten Fall als die einzige Möglichkeit betrachtet, so unterscheidet sich doch diese Form der Eiterung in der ganzen Art ihres Auftretens so wesentlich von dem Krankheitsbilde, welches man als acut infectiöse Phlegmone zo bezeichnen pflegt, dass eine Verwechselung kaum möglich ist.

Aehnlich wie bei der Einkeilung eines Fremdkörpers liegen die Verhältnisse bei Verbrennungen, Knorpelfracturen und anderen Traumen, bei denen sich ebenfalls ein ursprünglich rein seröses Transsudat durch unzweckmässiges Verhalten des Patienten in ein plastisches oder eiteriges Infiltrat verwandeln kann.

Eine etwas eigenthümliche Stellung in der Reihe der ätiologischen Momente nimmt die Erkältung ein. Es macht sich neuerdings das Betreben geltend, die ursprüngliche Bedeutung: gerade dieses Factors abzuschwächen, und da man früher mit demselben nicht eben wählerisch verfahren ist, so können wir uns jetzt eine etwas strengere Prüfung gewiss gern gefallen lassen. Andererseits dürfen wir aber nicht vergessen, dass eine ganze Reihe von Krankheitsfällen in ätiologischer Beziehung vollkommen dunkel bleibt, wenn wir die Erkältung, den einzigen Punkt, auf den der Bericht des Kranken mit Bestimmtheit hin- 
weist, in seiner ursächlichen Bedeutung nicht anerkennen wollen. So berichtet Gotts tein in der neuesten Auflage seines Lehrbuches über einige Fälle von Larynxödem, für deren Entstehung sich kaum ein anderer Grund als eben Erkältung ausfindig machen lässt, und ich selbst habe drei ganz ähnliche Fälle gesehen. Die Kranken waren etwas heiser, klagten über ein leichtes Druckgefühl in der Gegend des Kehlkopfes, eine Störung des Allgemeinbefindens lag überbaupt nicht vor. Bei der laryngoskopischen Untersuchung entdeckte ich zu meinem Erstaunen wohl ausgebildete Oedeme am Kehlkopfeingange. Alle drei Patienten führten ihre Erkrankung auf Erkältung zurück und alle drei waren nicht davon zu überzeugen, dass sie an einer immerhin ernsteren Affection litten und konnten sich nicht dazu verstehen, ihre geschäftliche Thätigkeit auf einige Tage auszusetzen. Trotzdem versehwand das Oedem und damit jede Spur ihrer Beschwerden unter Verabreichung von Eispillen in kürzester Frist.

Man hat derartige Fälle, wie ich sie eben geschildert habe, als "idiopathische Oedeme" bezeichnet; ich halte diesen Namen aber für unzweckmässig, weil er mir geeignet erscheint, falsche Vorstellungen vom Wesen der Sache zu erwecken. Diese Fälle sind doch nichts Anderes als rein entzündliche Oedeme, die abgesehen von ihrer Aetiologie, genau auf demselben Standpunkt stehen wie jedes andere entzündliche Oedem. Ihre Eigenthümlichkeit besteht ja auch nicht darin, dass auf Grund von Entzündungsvorgängen ein Oedem zu Stande kommt, sondern nur darin, dass ein so geringfügiger Reiz, der den Patienten gar nicht oder erst nachträglich zum Bewusstsein kam, eine so heftige Reaction hervorzurufen im Stande ist. Dasselbe Missverhältniss zwischen der Energie des Reizes und der durch denselben hervorgerufenen Reaction kann man ja auch bei den früher schon erwähnten Formen des Larynxödems constatiren, die bei gewissen Personen durch sonst ganz harmlose Höllensteineinpinselungen hervorgerufen zu werden pflegen. Hier wie dort wird man mit Fug und Recht eine besondere Empfindlichkeit der Kehikopfschleimhaut annehmen dürfen, aber man kann doch solche Oedeme kaum als "idiopathische" bezeichnen ${ }^{1}$ ).

1) s. meine Besprechung idiopathischer Erkrankungen in B. Fraenkel's Arch. f. Laryngol. Bd. II. H. 1. 1894. 
Lues und Tuberculose sind ebenfalls im Stande, auf Grund von entzündlichen Vorgängen, welche dieselben im Larynx ausgelöst haben (Perichondritis, Ulcerationen) Oedeme hervorzurufen, und derselbe Effect kann ausgelöst werden, wenn eine entzündliche Erkrankung, die sich in irgend einem dem Larynx benachbarten Organ abspielt, auf diesen übergreift.

Es bleibt nun noch die eine Frage zu beantworten, welche Ordnung und Namengebung für das umfangreiche Material, das ich eben nach Kräften zu sichten gesucht habe, am zweckentsprechendsten sei, und da möchte ich glauben, dass man, wie ich früher schon auseinandergesetzt habe, am besten thut, wenn man den bisher so wahllos gebrauchten Namen "Larynxödem" nur für diejenigen Erkrankungen reservirt, welche man früher als einfache und "passive Oedeme" bezeichnet hat. Diese sind dadurch charakterisirt, dass bei ihnen jede active Erkrankung des Kehlkopfes fehlt und dass das Larynxödem hier als eine Theilerscheinung mehr oder weniger allgemeiner hydropischer Ergüsse aufzufassen ist, die, eben weil sie in ihrer Entstehung von dem Ort, an dem sie sich finden, unabhängig sind, ihre seröse Natur durchgehends als constante Erscheinung bewahren.

In all' den Fällen aber, wo es sich um eine wirkliche entzündliche Localerkrankung des Kehlkopfs handelt, mag dieselbe infectiöser oder nicht infectiöser Natur sein, da hat sich das Oedem als ein so schwankendes Symptom erwiesen, dass es unzulässig wäre, dasselbe als Maassstab für irgend welche Eintheilung oder Namengebung zu verwenden. Dahingegen lässt sich die ganze Reihe der hierhergehörigen Affectionen zuvörderst einmal vom ätiologischen Standpunkt aus in die zwei eben schon angedeuteten Gruppen scheiden. Die eine umfasst alle diejenigen Erkrankungen, die ihre Entstehung einer acuten Infection verdanken und die demgemäss auch in ihrem klinischen Verhalten ganz dem Bilde einer acuten Infectionskrankheit entsprechen. In die zweite Gruppe gehören diejenigen Fälle, bei denen die Erkrankung durch Traumen, Erkältungen, constitutionelle Einflüsse und andere gleichwerthige ätiologische, entzündungserregende Momente, jedenfalls aber nicht durch acute Infectionen hervorgerufen wird: es weisen hier alle subjectiven und objectiven Erscheinungen in erster Reihe nur auf eine Affection des Kehlkopfes hin. 
Die Gefahren, die ja auch in diesen Fällen der Gesammtorganismus zu bestehen hat, haben nichts mehr mit dem Wesen der Erkrankung zu thun, sondern nur mit ihrer Localisation.

Beide Gruppen verhalten sich nun, wie wir das des früheren constatirt haben, in ihren pathologisch-anatomischen Verbältnissen ganz conform. Bei beiden hatten wir dieselben Krankheitsstadien in derselben Aufeinanderfolge zu beobachten Gelegenheit: Oedem, plastisches Infiltrat und eitrigen Zerfall des Gewebes. Jedes dieser drei Krankheitsstadien kann nun vollständig selbständig für sich in die Erscheinung treten, oder es können dieselben auch als Abstufungen ein und desselben pathologischen Prozesses sich der Reihe nach aus einander entwickeln; jedenfalls aber liegt ihnen allen, welcher Aetiologie sie auch sein mögen, ein gemeinschaftliches Moment zu Grunde, und das ist die Entzündung des Kehlkopfgewebes, die Laryngitis. Dieser Factor ist nicht nur ein allen Krankheitsstadien gemeinschaftlicher, er ist auch wichtig genug, um bei der Ordnung und der Terminologie der ganzen Materie eine entscheidende Rolle zu spielen. Allerdings bedarf derselbe noch einer genauen Präcision, die durch irgend eine Zusatzbestimmung geschaffen werden muss. Da giebt uns denn die Geschichte des Larynxödems drei Bezeichnungen an die Hand, durch welche frühere Autoren diesem $Z$ wecke zu entsprechen versuchten, der eine sprach von einer Laryngitis phlegmonosa, der zweite von einer Laryngitis infiltrata, der dritte von einer Laryngitis submucosa. Die ersten beiden Benennungen sind kaum zu empfehlen: denn wir "sind nicht gewohnt ein rein seröses Transsudat, wie es sich bei dem ersten der drei in Betracht kommenden und unter einem Gesichtspunlte zusammenzufassenden Krankheitsbilder vorfindet, unter den Begriff der Phlegmone oder des Infiltrats za subsumiren. So bleibt nur noch, da ich keinen besseren Namen ausfindig zu machen im Stande bin, die Bezeichnung „Laryngitis submucosa" übrig. Allerdings müssen wir auch bei dieser einige Unzulänglichkeiten mit in den Kauf nehmen; denn einmal ist, wie wir gesehen haben, die Submucosa durchaus nicht immer allein erkrankt, und dann haben wir auch mancherlei Gründe kennen gelernt, welche dafür sprechen, dass ein serös entzündliches Transsudat unter Umständen auch auf Grund eines nur 
die Mucosa schädigenden Reizes zu Stande kommen kann. Diese Einwände, die man immerhin zu machen berechtigt ist, müssen aber in den Hintergrund treten gegenüber der Erwägung, dass all' die in Betracht kommenden Veränderungen, auf Grund deren wir überhaupt erst eine Diagnose zu stellen vermögen, ihren hauptsächlichen und vorwiegenden Sitz in der Submucosa haben. Diese unbestreitbare Thatsache dürfte, besonders wenn wir die vorher gemachten Einschränkungen im Auge behalten, meines Erachtens wohl genügen, um die Bezeichnung "Laryngitis submucosa" zu rechtfertigen.

Es würde sich demnach folgendes Schema ergeben.

\section{A. Laryngitis submucosa acuta}

umfasst alle diejenigen Erkrankungen, bei denen die Submucosa den vorwiegenden Sitz der auf entzündlichen Vorgängen beruhenden Gewebsveränderungen bildet. Dieselben können sein:

1) acut infectiöser Natur, und sind dann aufzufassen als acute Infectionskrankheiten, bei denen das inficirende Virus den Larynx als Eingangspforte in den Organismus benutzt hat (primäre Erkrankung). Andererseits kann aber der Larynx auch im Verlauf einer bereits bestehenden Infectionskrankheit (Erysipel, Scarlatina, Typhus u. s. w.) von dem inficirenden Virus betroffen werden, und auch diese consecutiven Erkrankungen wären dann, so weit sie die Submucosa angehen, an dieser Stelle unterzubringen (secundäre Erkrankung).

Nach dem pathologisch-anatomischen Befund haben wir zu unterscheiden:

a) Stadium oedematosum. - Larynxerysipel.

b) Stadium plasticum

c) Stadium suppurativum $\}$ acut infectiöse Phlegmone.

2) nicht infectöser Natur; als ätiologische Momente kommen in Betracht: Verbrenuungen, Fremdkörper, Fracturen und Zerreissungen, Erkältung, gewisse Arzneimittel (?), Eutzündungsvorgänge in der Nachbarschaft des Kehlkopfes und constitutionelle Erkrankungen (Lues und Tuberculose).

Nach dem pathologisch-anatomischen Befund haben wir zu unterscheiden wie vorhin: 
a) Stadium oedematosum.

b) Stadium plasticum.

c) Stadium suppurativum.

B. Larynxödem

umfasst alle diejenigen Erkrankungen, bei denen das Oedem des Kehlkopfes einen Folgezustand anderweitiger, sei es localer, sei es allgemeiner Krankheitsprozesse darstellt. Jeder active Reizzustand des Kehlkopfes fehlt bei diesem Krankheitsbild. In ätiologischer Bezichung kommen hier in Betracht: Gefäss-, Herzund Nierenleiden, venöse Stauungen, allgemeine Anämie und Hydrämie, angioneurotische Prozesse (?).

Zum Schluss noch ein Wort über diejenigen Veränderungen, welche sich geltend machen, wenn die eine oder die andere der vorher geschilderten Affectionen von dem acuten in ein chronisches Stadium tritt.

Beim chronischen Larynxödem erleidet die chemische Natur des Transsudates einige Veränderungen, die für unsere augenblickliche Betrachtung von keinem besonderen Interesse sind. Ausserdem werden bei längerer Dauer des Leidens die Wandungen der Gefässe allmählich schadhafter und durchlässiger, und eine grössere Anzahl weisser Blutkörperchen findet jetzt ihren Weg in das benachbarte Gewebe, das im Beginn der Erkrankung nur ein seröses Transsudat ohne jede Beimischung körperlicher Elemente aufzuweisen hatte (Eppinger S. 66). Eine Verwechslung mit entzündlichen Infiltrationsvorgängen ist auch in diesem Stadium nicht za fürchten, da alle sonstigen local entzündlichen Erscheinungen fehlen.

Die submucöse Laryngitis kann nur so lange, als sie sich im ödematösen oder plastischen Stadium befindet, $\mathrm{zu}$ einem chronischen Leiden werden. Die Veranlassung hierzu ist gegebenen Falles entweder in constitutionellen Ursachen oder in einer unzwẹckmässigen Lebensführung des Patienten zu suchen, durcl welche die Ausheilung einer bestehenden Erkrankung verhinder wird. In solchen Fällen pflegt das kleinzellige Infiltrationsmaterial das schliesslich selbst die tiefen Muskelschichten in dichten Zü gen durchsetzt, sich ganz allmählich zu assimiliren und meh oder weniger hochgradige hyperplastische Zustände hervorzurufen 